\title{
Consistent Posttest Calculations for LOCA Scenarios in LOBI Integral Facility
}

\author{
F. Reventós, ${ }^{1}$ P. Pla, ${ }^{2}$ C. Matteoli, ${ }^{1,3}$ G. Nacci, ${ }^{1,3}$ M. Cherubini, ${ }^{3}$ A. Del Nevo, ${ }^{3}$ and F. D'Auria ${ }^{3}$ \\ ${ }^{1}$ Department of Physics and Nuclear Engineering, Technical University of Catalonia (UPC), Diagonal 647, 08028 Barcelona, Spain \\ ${ }^{2}$ European Commission, Joint Research Centre (JRC-IE), Institute for Energy 1755 ZG, Petten, The Netherlands \\ ${ }^{3}$ San Piero a Grado Nuclear Research Group, University of Pisa (GRNSPG-UNIPI), 56126 Pisa, Italy
}

Correspondence should be addressed to F. Reventós, francesc.reventos@upc.edu

Received 22 May 2011; Accepted 15 September 2011

Academic Editor: Klaus Umminger

Copyright ( 2012 F. Reventós et al. This is an open access article distributed under the Creative Commons Attribution License, which permits unrestricted use, distribution, and reproduction in any medium, provided the original work is properly cited.

\begin{abstract}
Integral test facilities (ITFs) are one of the main tools for the validation of best estimate thermalhydraulic system codes. The experimental data are also of great value when compared to the experiment-scaled conditions in a full NPP. The LOBI was a single plus a triple-loop (simulated by one loop) test facility electrically heated to simulate a $1300 \mathrm{MWe}$ PWR. The scaling factor was 712 for the core power, volume, and mass flow. Primary and secondary sides contained all main active elements. Tests were performed for the characterization of phenomenologies relevant to large and small break LOCAs and special transients in PWRs. The paper presents the results of three posttest calculations of LOBI experiments. The selected experiments are BL-30, BL-44, and A1-84. They are LOCA scenarios of different break sizes and with different availability of safety injection components. The goal of the analysis is to improve the knowledge of the phenomena occurred in the facility in order to use it in further studies related to qualifying nodalizations of actual plants or to establish accuracy data bases for uncertainty methodologies. An example of procedure of implementing changes in a common nodalization valid for simulating tests occurred in a specific ITF is presented along with its confirmation based on posttests results.
\end{abstract}

\section{Introduction}

Experimental data recorded in integral test facilities (ITFs) are traditionally used in order to validate best estimate (BE) system codes and to investigate the behaviour of Nuclear Power Plants (NPPs) under accidental scenarios. Posttest calculations are the normal practice carried out with this purpose. Further studies bring the analysts to go into deeper considerations like using posttest results either to establish comparisons in the frame of the so-called scaling calculations [1] or to evaluate accuracy [2]. The former is, by now, part of methodologies used by the authors in order to qualify nodalizations [3], while the latter is at the basis of the establishment of accuracy data bases used by CIAU uncertainty methodology.

The current practice intends, on the one hand to fulfil the usual goals of conventional posttests, and on the other hand to add some further value to the results by means of what the authors understand by mutual consistency among the calculations. The most important aspect of this mutual consistency is to simulate as many tests as possible by using the same nodalization of the involved ITF. Once a nodalization change carried out for one specific test results in a clear improvement of the predictions, it is useful to recalculate all the other tests and to check if the change is accepted and confirmed. Some explanation will be given on this point in several paragraphs below.

Three different LOBI tests have been selected in order to be simulated. They are all LOCA scenarios with break sizes between 5 and 10\%. Relevant phenomena occurring in such scenarios are the main subject of investigation.

The test BL-30 was a 5\% small break LOCA in the cold leg performed in the LOBI-MOD2 facility on April 15th 1989. The objectives of the test were to identify and/or verify major phenomenologies relevant to the response of a PWR to an SB LOCA, with particular reference to overall mass distribution, loop seal formation and clear-out and eventual core uncover. Other objective was the assessment of ECCs 
effectiveness in the SB LOCA scenarios having the potential to cause temperature excursions in the core.

The test BL-44 was a $6 \%$ small break LOCA in the cold leg performed in the LOBI-MOD2 facility on April 26th 1990. The objective of the test was to enrich the experimental database with a Counter Part Test having high value for code assessment and scalability, in particular with reference to the problem of initial power scaling in SB LOCAs. Phenomenological objectives were the identification of the mass distribution in the primary system (PS), loop seal behaviour, core heatup, and rewet and accumulator performance.

The test A1-84 was a 10\% break LOCA in the hot leg performed in the LOBI-MOD2 facility on October 14th 1985. The test belongs to the A-Matrix of the LOBI-MOD2 defined by the German contract partner. The objective of the test was to investigate the general system thermalhydraulic response during the course of the LOCA.

The three tests were LOCA scenarios performed with the same LOBI configuration, and an important part of hardware considerations was the same for the three tests as will be explained below.

Other similarities and differences in boundary conditions were identified. The size of the break was similar in two of them (BL-30 and BL-44) and different in the other. Two of them (in this case BL-30 and A1-84) had a secondary side cooldown, while, in the other, the secondary side was isolated.

The existing slight difference between break sizes of BL30 and BL-44 could result in a slight quicker depressurization and as a consequence an advance of accumulator injection. The total failure of HPIS in BL-44 (while in BL-30 only $50 \%$ failed) could have a direct influence on core dryout. Each relevant thermalhydraulic aspect appearing in more than one test has been identified and considered consistent when the expected behavior on the given test was in accordance with the explanation produced from the apparent differences in boundary conditions.

The calculations have been carried out using the same code version and the same basic nodalization. Similarities and differences such as those depicted above have been carefully checked and unjustified distinctions strictly avoided.

\section{The LOBI-MOD2 Facility and Hardware Considerations}

The LOBI (LWR off-normal behaviour investigation) was a reactor thermalhydraulic safety research programme carried out by the EC JRC Ispra site [4]. The main objective was the investigation of basic phenomenologies governing the thermalhydraulic response of an ITF for a range of PWR operational and accident conditions; the programme was also aimed to the provision of an experimental data base for the development and improvement of analytical models and assessment of system codes used in LWR safety analysis.

The LOBI test facility (Figure 1) was a single plus a triple-loop (simulated by one loop) full-power high-pressure integral system test facility representing an 1:712 scale (core power, volume, and mass flow) model of a 4-loop, $1300 \mathrm{MWe}$
PWR (KWU type). It incorporates the essential features of a typical PWR primary and secondary cooling system. The test facility was commissioned in December 1979 and was operated until June 1982 in the MOD1 configuration for the investigation of large break LOCAs; it was then extensively modified into the MOD2 configuration which was operated from April 1984 to June 1991 for the characterization of phenomenologies relevant to small break LOCAs and special transients in PWRs. The measurement system comprised a total of about 470 measurement channels which allowed the measurement of all relevant thermal-hydraulic quantities at the boundaries (inlet and outlet) of each major primary and secondary system loop component and within the reactor pressure vessel model and steam generators. A process control system allowed the simulation of time- or pressuredependent parameters such as core decay heat release, main coolant pump hydraulic behaviour, and safety injection flow rates. A fast running data acquisition system complemented the experimental installation.

Experimental data and documentation of tests performed at the facility are available online for code validation purposes through the JRC STRESA (storage of thermal reactor safety analysis data) web database platform [5], which was developed with the objective of the preservation of these amounts of thermalhydraulic experimental data produced in ITFs programmes and the associated supporting information/documentation.

The following paragraphs include an explanation on hardware considerations for LOBI-MOD2 experiments BL$30[6,7], \mathrm{BL}-44[8,9]$, and A1-84 $[10,11]$.

Each paragraph covers one related item and stresses on hardware similarities and differences among the three considered tests. In case no reference to any specific test is given, the piece of hardware is identical in three experiments.

For tests BL-30 (single-ended 5\% break, orifice diameter $6.7 \mathrm{~mm}$ ) and BL-44 (single-ended 6\% break, orifice diameter $7.36 \mathrm{~mm}$ ) the break assembly consisted of a T-shaped spool piece located in the cold leg, between the main coolant pump and the pressure vessel inlet. For test A1-84 the break assembly consisted also of a T-shaped spool piece but inserted within the hot leg pipe work (single ended 10\% break orifice, diameter $9.5 \mathrm{~mm}$ ). In all tests, break includes a side-oriented break orifice, a quick opening on/off valve for initiation of the rupture and a measurement insert for density, velocity as well as pressure, and temperature of the outflow. The break outflow is diverted to a condensing tank system where it is collected and measured.

The externally mounted upper head is connected to the upper plenum and to the upper downcomer, in all tests. An additional connection exists between the downcomer and the top of the upper head and this is used for conditioning the fluid in the upper head to about the temperature of the downcomer. This line is normally isolated sufficient time before transient initiation.

In all tests, the by-pass flow between upper downcomer and upper plenum includes three main flow paths: (1) upper head connection lines (about 1\% nominal flow in the three tests); (2) two holes of diameter $5 \mathrm{~mm}$ in the core barrel tube, each connecting downcomer and upper plenum at 


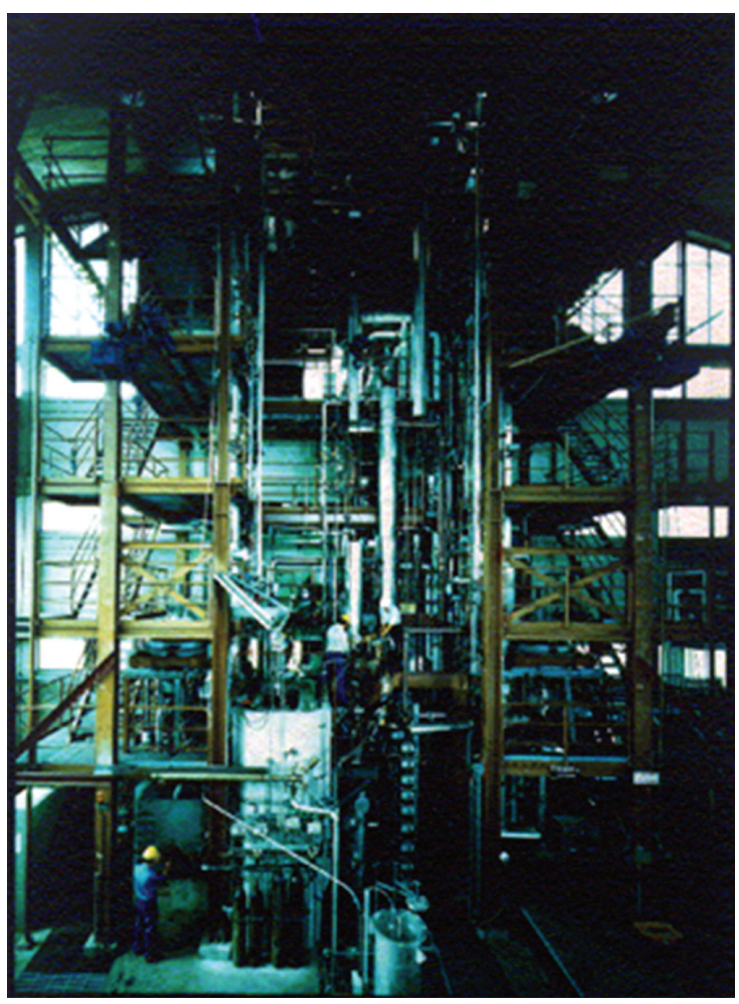

(a)

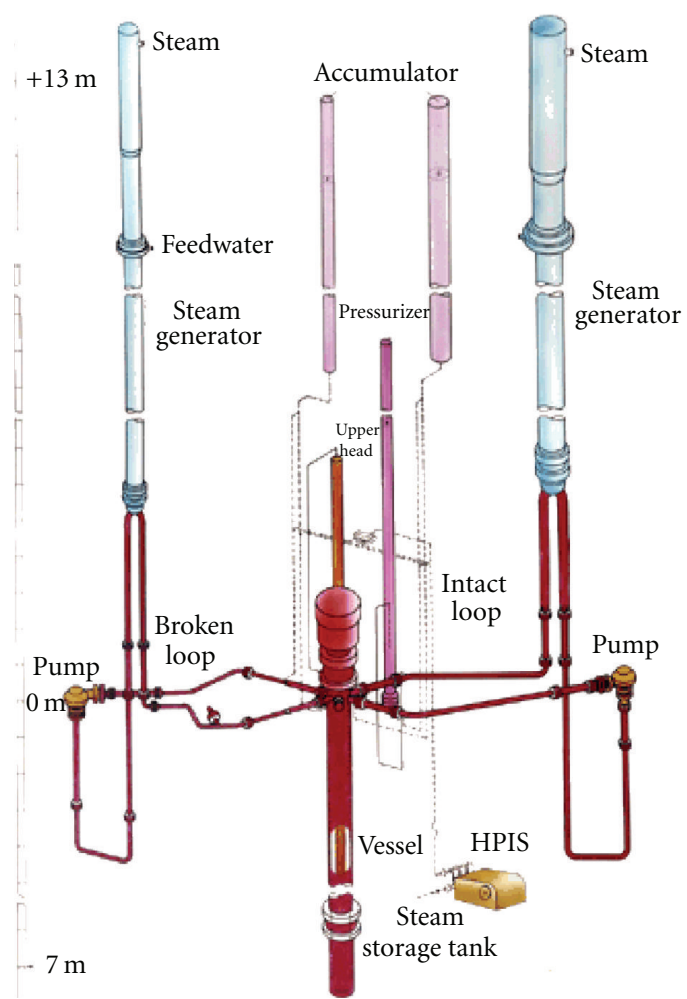

(b)

FIGURE 1: LOBI-MOD2 test facility and schematic representation of the cooling system (STRESA JRC database).

the uppermost elevation; (3) possible hot leg to core barrel clearance fit. The sum of (2) and (3) by-pass flows mentioned has been estimated at 2.4 to $3.7 \%$ of nominal core flow.

Main Coolant Pumps Seal Water Drainage. Before the initiation of the experiments, the fraction of cooling water which enters the primary system is normally drained from the upper plenum using the pressurizer water level control system. During the transient, the draining system is isolated and the injected seal water is added to the inventory of the primary system in test A1-84. The LOBI-MOD2 test facility has also a closed loop pump seal water compensation system with drainage from the lower plenum, generally activated in SB LOCAs, which is activated in the two other tests.

The locked rotor hydraulic resistance of the LOBI main coolant pumps is used to obtain the same resistance as in the reference reactor. To ensure a more symmetrical mass flow behavior in both pumps during period of natural circulation following pump coast down, the pump-locked rotors are installed at the pump discharge, each consisting in a valve that can be properly orificed to provide the required additional resistance. In the intact loop, this resistance is negligible, but in the broken loop it is significant and a perforated plate type orifice is installed. In the tests, the orifice provides an area reduction of about $18 \%$ of the normal flow area, and it is normally inserted $4 \mathrm{~s}$ after pump coast down to zero speed.

In tests BL-30 and A1-84 additional transient assumptions were typical of the LOBI reference reactor, the German
Biblis B plant; as such a symmetric cooldown of the two Steam Generators (SG) at $100 \mathrm{~K} /$ hour was imposed after SCRAM. Cooldown is achieved via steam venting from the SG relief valves. Cooldown procedure is not considered in test BL-44.

ECCS water is injected into the primary loops through the accumulators and the low- and high-pressure injection system (LPIS, HPIS).

In BL-30 and BL-44 tests, the accumulator was connected to the intact loop cold leg only. In order to avoid unrealistic frequent opening and closing of the valve, due to the LOBI accumulators pressure control system, an orifice with a diameter of $8 \mathrm{~mm}$ (in BL-30) and of $7.2 \mathrm{~mm}$ (in BL-44) was inserted in the injection line. In A1-84 test, the accumulators are connected to both legs of the intact loop and to the cold leg of the broken loop.

In BL-30 test, the HPIS was connected to the intact loop cold leg only, simulating 2 of 4 pumps. In test A1-84, the HPIS is connected to the hot leg of the intact loop, simulating 2 of 4 pumps. The remaining two pumps (that exist in the reference plant) are assumed to be one in maintenance and the other connected to the broken loop. In BL-44 only the LPIS was available for both loops cold leg at a rate of $0.4 \mathrm{~kg} / \mathrm{s}$ and activated on high heater rod temperature.

The pressurizer surge line was connected to the intact loop hot leg in BL-30 and A1-84 tests and to the broken loop hot leg in BL-44 test.

Main feedwater (FW) was not available in all tests. In test BL-30, auxiliary feedwater (AFW) was available for both 
TABLE 1: LOBI-MOD2 tests BL-30, BL-44, and A1-84 experimental and calculated steady-state values.

\begin{tabular}{|c|c|c|c|c|c|c|}
\hline \multirow{2}{*}{ LOBI Parameter (Units) } & \multicolumn{2}{|c|}{ BL-30 } & \multicolumn{2}{|c|}{ BL-44 } & \multicolumn{2}{|c|}{ A1-84 } \\
\hline & Experiment & Calculation & Experiment & Calculation & Experiment & Calculation \\
\hline Core thermal power (MWth) & 5.17 & 5.17 & 5.24 & 5.25 & 5.15 & 5.15 \\
\hline PRZ pressure (top of the PRZ) (MPa) & 15.80 & 15.80 & 15.46 & 15.46 & 15.80 & 15.80 \\
\hline SG-IL pressure (top of the SG) (MPa) & 6.530 & 6.531 & 5.11 & 5.11 & 6.548 & 6.550 \\
\hline SG-BL pressure (top of the SG) (MPa) & 6.510 & 6.504 & 5.120 & 5.119 & 6.527 & 6.526 \\
\hline Accumulator IL pressure (MPa) & 2.77 & 2.77 & 3.91 & 3.91 & 2.8 & 2.8 \\
\hline Primary mass inventory $(\mathrm{kg})$ & 430.95 & 440.62 & 448.0 & 465.05 & 432.86 & 440.33 \\
\hline Core inlet temperature $(\mathrm{C})$ & 295.97 & 295.31 & 280.50 & 280.15 & 295.22 & 295.33 \\
\hline Core outlet temperature (C) & 327.31 & 325.81 & 313.0 & 312.23 & 326.76 & 326.91 \\
\hline Hot leg IL temperature (C) & 326.00 & 325.68 & 311.39 & 312.10 & 328.94 & 326.91 \\
\hline Hot leg BL temperature (C) & 327.00 & 325.63 & 314.84 & 312.05 & 329.4 & 326.9 \\
\hline Cold leg IL temperature (C) & 295.00 & 293.59 & 281.24 & 278.32 & 294.23 & 293.87 \\
\hline Cold leg BL temperature (C) & 294.00 & 293.34 & 280.07 & 278.27 & 292.29 & 292.21 \\
\hline Hot leg IL mass flow $(\mathrm{kg} / \mathrm{s})$ & 20.76 & 20.42 & 21.30 & 21.15 & 20.2 & 20.02 \\
\hline Hot leg BL mass flow $(\mathrm{kg} / \mathrm{s})$ & 6.92 & 6.98 & 7.40 & 7.23 & 6.2 & 6.175 \\
\hline SG-IL feedwater mass flow $(\mathrm{kg} / \mathrm{s})$ & 1.99 & 1.99 & 1.95 & 2.11 & 2.07 & 2.038 \\
\hline SG-BL feedwater mass flow $(\mathrm{kg} / \mathrm{s})$ & 0.69 & 0.69 & 0.75 & 0.71 & 0.61 & 0.643 \\
\hline Pressurizer level, collapsed (m) & 5.10 & 5.10 & 5.03 & 5.03 & 5.346 & 5.346 \\
\hline Core pressure drop $(\mathrm{kPa})$ & 117.16 & 121.54 & 125.0 & 125.86 & 112.59 & 118.4 \\
\hline IL Pump velocity (rpm) & 4896.86 & 4896.65 & 4834.99 & 4831.95 & 4832.93 & 4927.43 \\
\hline BL Pump velocity (rpm) & 3812.61 & 3812.54 & 3822.72 & 3829.26 & 3912.36 & 3911.94 \\
\hline
\end{tabular}

loops, but used for the broken loop SG only. AFW was not used in tests BL-44 and A1-84.

\section{Nodalization and Steady-State Calculations}

The RELAP5 Mod 3.3 nodalization input deck was based on the same approach of original previous works performed for LOBI test BL-44 either in cooperation between the two universities [12] or at the University of Pisa, [13, 14]. All these previous calculations were performed with RELAP5 Mod 3.3. Older results, like those obtained at the Technical University of Catalonia for LOBI test BL-30 [15] or at JRC Ispra [16] with previous version of the code (RELAP5 Mod 2.5), were also taken into account only as preceding information.

The input deck reflects as far as possible hardware configuration described in Section 2. Boundary and initial conditions are set up according with the tests specifications. The prediction of the break flow rate is important when LOCAs are simulated. Ransom and Trapp [17] chocked flow model is activated at break in these three tests. Since discharge structure was the same, discharge coefficients used had the same value for all tests; in this sense unjustified distinctions were avoided as usual.

A schematic representation of the original nodalization is shown in Figure 2. The purpose of showing such diagram is only to illustrate the degree of detail used for the analyses performed.

The initial conditions of the experimental tests (BL-30, BL-44, and A1-84) are compared with the achieved steady state results of the code simulations; see Table 1 that shows for every test the agreement between each experiment and its corresponding calculation.

Usual steady-state controllers have been set in order to stabilize the nodalization. Pressures are imposed by means of Relap5 time-dependent volumes removed later on. Main feedwater is controlled trying to match SG levels and a fictitious charging system is set to establish the right pressurizer level.

Once each steady state is achieved properly, one additional comment can be made related to what has been announced as consistency checks between the three different calculations performed. It is a comment related to temperature ranges in primary and secondary sides.

BL-44 secondary pressure is established at about 5.1 MPa, while in the other two tests it takes a value of about 6.5 MPa. This brings to saturation temperatures of $265^{\circ} \mathrm{C}$ for BL-44 secondary side and $281^{\circ} \mathrm{C}$ for the other two tests. Under these conditions, BL-44 steady-state values for primary temperatures stabilize at about $296^{\circ} \mathrm{C}$ (CL) and $327^{\circ} \mathrm{C}(\mathrm{HL})$ with temperature differences between primary and secondary sides, respectively, of $15^{\circ} \mathrm{C}$ and $46^{\circ} \mathrm{C}$. For the other tests these values are $280^{\circ} \mathrm{C}(\mathrm{CL})$ and $313^{\circ} \mathrm{C}$ (HL) with temperature differences, respectively, of $15^{\circ} \mathrm{C}$ and $48^{\circ} \mathrm{C}$. This similarity in temperature differences between primary and secondary side shows the consistency with the fact that heat transfer from primary to secondary side occurs at similar mass flows, identical heat transfer correlations (same code version), and SG nodalization (reflecting an identical SG geometry). 


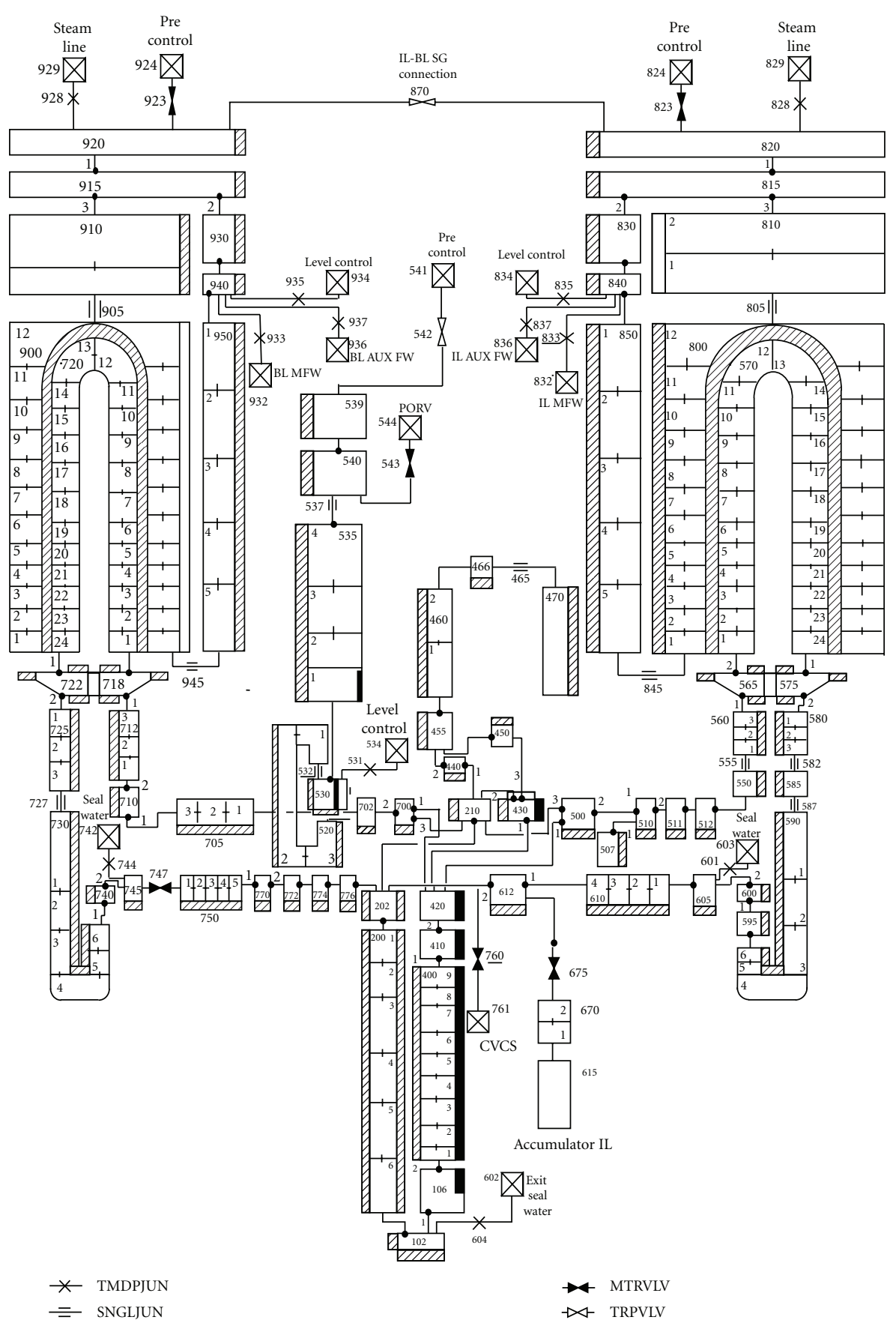

FIgURE 2: LOBI-MOD2 nodalization for relap code.

\section{BL-30 Scenario}

\subsection{Experiment Description}

The test BL-30 was a 5\% small break LOCA in the cold leg performed in the LOBI-MOD2 facility. The test included the hardware configuration presented in Section 2. The general objective of the test was to reproduce major phenomena relevant to the response of a PWR to SB LOCA and to provide data for: mass distribution, loop seal formation and clearance, eventually core uncover, and assessment of ECCS effectiveness in SB LOCA scenarios. Some main set points of test BL-30 are shown in Table 2 (all pressures values, if not specified, correspond to UP) together with the sequence of experimental events and calculated simulation.

Initial and boundary conditions were applied as specified.

After rupture of break device, PS started to depressurize reaching pressure signal SCRAM at $13.2 \mathrm{MPa}$ and $2.8 \mathrm{~s}$ and leading to saturation in hot legs, upper plenum and surge line. Power-time curve was applied to the electrically heated 
TABLE 2: Sequence of main events for test BL-30 experimental and posttest calculation.

\begin{tabular}{|c|c|c|}
\hline Events/set points & $\begin{array}{c}\text { Time after } \\
\text { experiment } \\
\text { initiation }(\mathrm{s})\end{array}$ & $\begin{array}{l}\text { Calculated time } \\
\text { after transient } \\
\text { initiation }(\mathrm{s}) \\
\end{array}$ \\
\hline Break opening & 0.0 & 0.0 \\
\hline $\begin{array}{l}\text { Secondary side cooldown } \\
100 \mathrm{~K} / \mathrm{h} \text { actuation (at } 13.2 \mathrm{MPa} \text { ) }\end{array}$ & 2.3 & 1.62 \\
\hline $\begin{array}{l}\text { SCRAM signal (at } 13.2 \mathrm{MPa}+ \\
\text { delay } 0.5 \mathrm{~s} \text { ) }\end{array}$ & 2.8 & 2.12 \\
\hline Saturation in hot legs & 4.9 & 3.0 \\
\hline Saturation in upper plenum & 5.0 & 3.0 \\
\hline Pressure in PS $11.7 \mathrm{MPa}$ & 7.0 & 8.01 \\
\hline $\begin{array}{l}\text { MCPs start coastdown (at } \\
10.8 \mathrm{MPa})\end{array}$ & 9.0 & 10.8 \\
\hline Pressurizer surge line uncovers & 19.2 & 20.0 \\
\hline $\begin{array}{l}\text { HPIS actuation (at } 11.7 \mathrm{MPa}+ \\
\text { delay } 35 \mathrm{~s} \text { ) }\end{array}$ & 42.0 & 43.01 \\
\hline Saturation in lower plenum & 42.0 & 34.0 \\
\hline MCPs stop & 79.0 & 80.0 \\
\hline $\begin{array}{l}\text { PS pressure falls below SS } \\
\text { pressure }\end{array}$ & 188.0 & 211.0 \\
\hline Broken loop seal clearance & 200.0 & 275.0 \\
\hline Break uncovers & 200.0 & 277.0 \\
\hline Intact loop seal clearance & 230.0 & 273.0 \\
\hline $\begin{array}{l}\text { Occurrence of minimum } \\
\text { primary side mass }\end{array}$ & 623.0 & 580.0 \\
\hline $\begin{array}{l}\text { Accumulator actuation (at } \\
2.8 \mathrm{MPa} \text {, disabled when } \\
\text { accumulator water volume is } 221 \\
\text { ( } 5 \% \text { of total volume) })\end{array}$ & 625.0 & 579.9 \\
\hline $\begin{array}{l}\text { Auxiliary feedwater in broken } \\
\text { loop (SG level }<5 \mathrm{~m}) \text {, at } 7 \% \text { of } \\
\text { the nominal initial flow and } \\
150^{\circ} \mathrm{C}\end{array}$ & 1023.0 & 1070.0 \\
\hline Accumulator injection stops & 1683.0 & 2130.0 \\
\hline End of the test & 1683.0 & 2790.0 \\
\hline
\end{tabular}

rod bundle; the heated power remained at 100\% till SCRAM, afterwards it simulated decay power and release of stored energy.

At the same time, trip signals for secondary-side isolation and MCP coastdown were generated. MCPs coasted down in accordance with the specified curves at $9 \mathrm{~s}$ till $79 \mathrm{~s}$. The main FW in both SGs remained nominal till $2.8 \mathrm{~s}$, afterwards SGs were isolated (main FW lines and main steam lines closed). The secondary sides of both SGs remained, however, connected during the entire test. Cooldown was applied at $100 \mathrm{~K} / \mathrm{h}$ after $13.2 \mathrm{MPa}$ PS trip signal. Cooldown was controlled and achieved through SRV venting.

HPIS was directed into the intact loop cold leg when PS pressure was $8.5 \mathrm{MPa}$. The programmed flow-versuspressure curve was matching the capacity of 2 out of 4 HPIS trains.

At $42 \mathrm{~s}$ PS reached the saturation pressure of the fluid in the lower plenum. Primary to secondary heat transfer degraded. When the forced circulation (driven by MCPs) stopped, the onset of two phase natural circulation and of the reflux condenser heat transfer modes, is essentially shattered by the early voiding of the upper parts of the primary system and by the loss of the heat sink (steam generators), as the secondary pressure overtakes the primary one. At $188 \mathrm{~s}$ the PS pressure fell below the SS pressure and reverse heat transfer in the SGs was established. The break uncovered at about $200 \mathrm{~s}$ causing reduction of break flow which was compensated by HPIS flow. Broken and intact loops seals started to clear at about $200 \mathrm{~s}$ and $230 \mathrm{~s}$, respectively.

Accumulator injection was activated at $625 \mathrm{~s}$ when PS pressure was $2.7 \mathrm{MPa}$ and accumulator was disabled when the water volume had decreased to $5 \%$ of its total volume. Primary system mass inventory decreased and started to recover after accumulator intervention.

AFW was activated in the SG of the broken loop due to achievement of SG downcomer level to $5 \mathrm{~m}$, while in the SG of the intact loop the level was always higher than the specified set point.

The vessel liquid level was never low enough to cause the uncover of the heater rod bundle. Adequate core cooling was ensured by sufficient PS mass inventory replenish by ECCS. Rod surface temperature decreased following saturation temperature. Test was terminated when PS pressure arrived to $0.9 \mathrm{MPa}$.

Figure 3 shows a snapshot of a video of the experimental real-time collapsed levels and plots of primary and secondary pressures.

4.2. Posttest Calculation. The input deck used reflects as far as possible hardware configuration described in Section 2 and imposes initial, boundary conditions and set points shown in Table 2; one HPIS pump was used for the intact loop representing 2 of 4 pumps, one accumulator in the intact loop was simulated and cooldown of $100 \mathrm{~K} / \mathrm{h}$ was adjusted to both SGs experimental values.

The sequence of the main events is summarized in Table 2 for the calculation compared to the BL-30 experiment. The agreement is quite close.

The results of the BL-30 experiment calculation (descriptor BL30POST) are shown plotted in the following figures compared with the experimental data (descriptor EL30) and described below.

Figure 4 shows PS (pressurizer) pressure, the depressurization, and the change of depressurization rate after the break uncover (at about $250 \mathrm{~s}$ ) is correctly simulated. On the long term, both pressures decrease with same rate.

Figure 5 shows SS pressure, in the broken loop (vols. 87,915 ) and intact loop (vols. 97, 815) for the experiment and BL-30 calculation. Pressure increases till SRV opens at 8.3 $\mathrm{MPa}$ and few seconds' later secondary side cooldown $(100 \mathrm{~K} / \mathrm{h})$ starts: cooldown behaviour was correctly simulated in the calculation.

Figure 6 shows the ECCS (HPIS mass flow and accumulators mass injected) together with the integral mass flow flowing out of the break. HPIS mass flow is injecting from the beginning of the transient in the PS depending on PS 


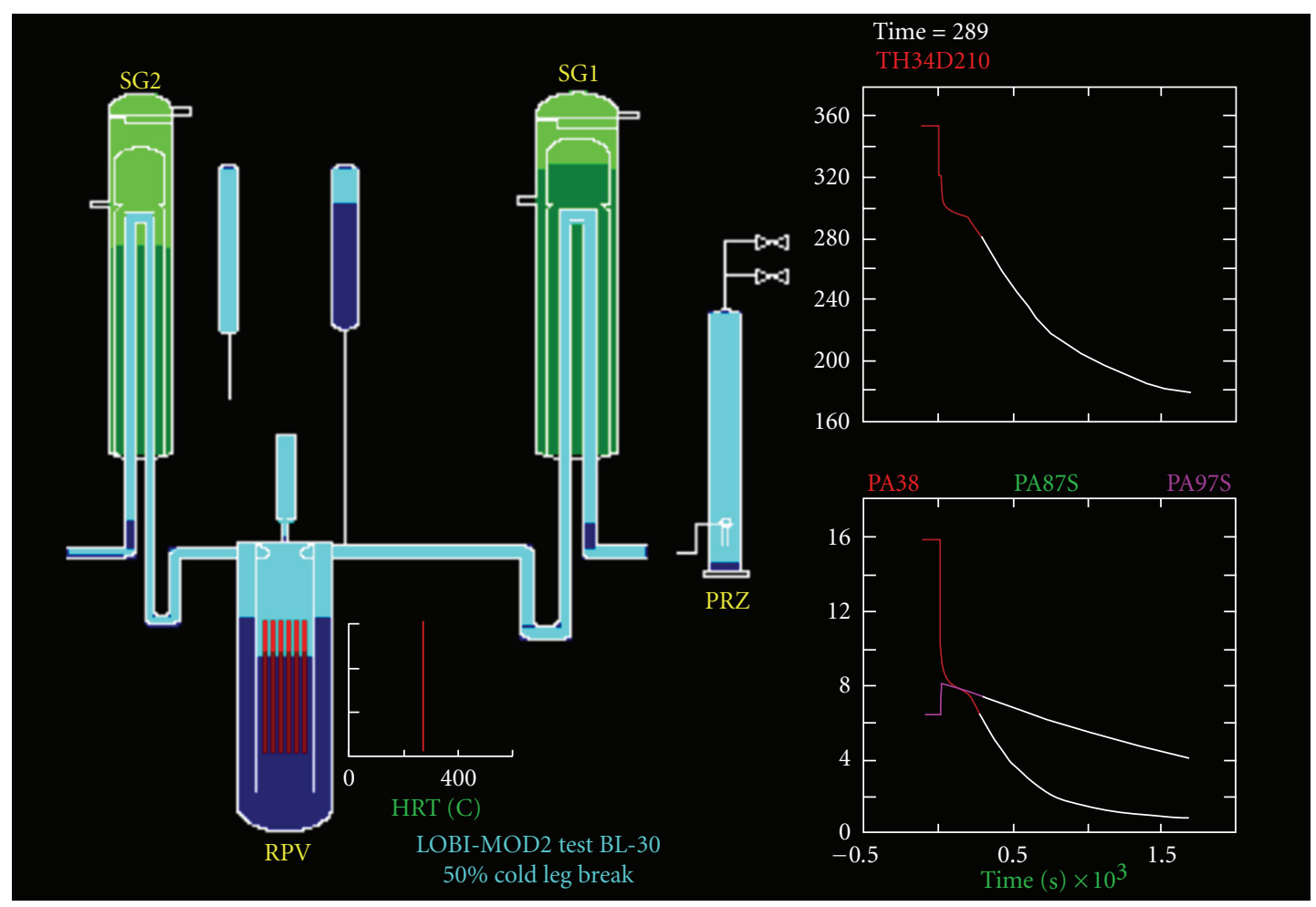

FIGURE 3: BL-30 experiment collapsed levels display and primary and secondary pressures (STRESA JRC database).

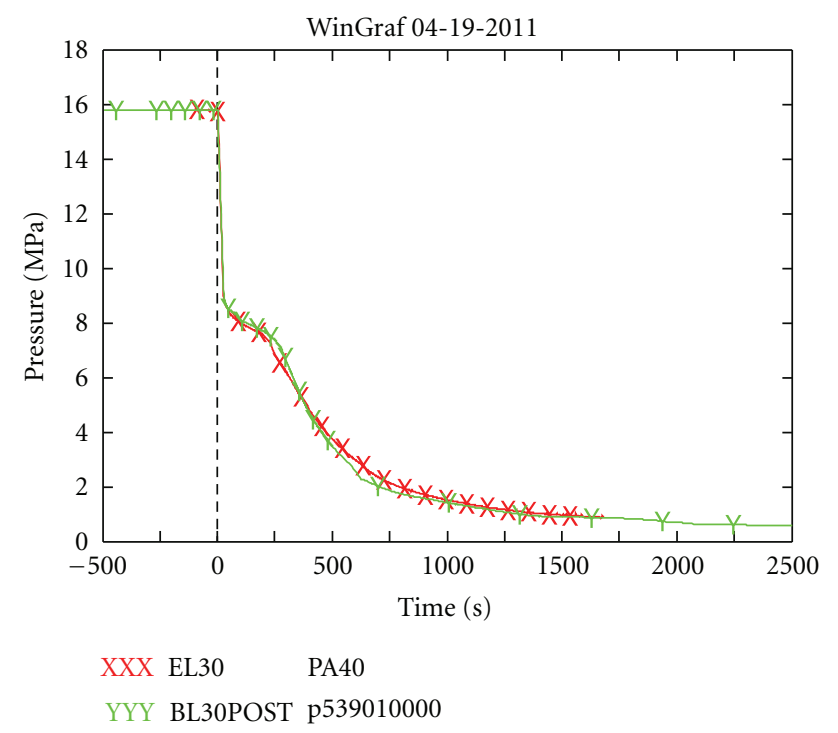

FIGURE 4: Primary system pressure.

pressure (lower pressure means more injection power). At about $580 \mathrm{~s}$ the accumulator starts to inject dependent also on PS pressure trend. In general, good agreement is obtained for the ECCS mass flow in the calculation compared to the BL-30 experiment.

Figure 7 shows PS total mass. It decreases after the break and starts to recover due to HPIS and accumulators injection.

Figure 8 shows fuel cladding temperatures at different heights in the core region, no dryout is observed and

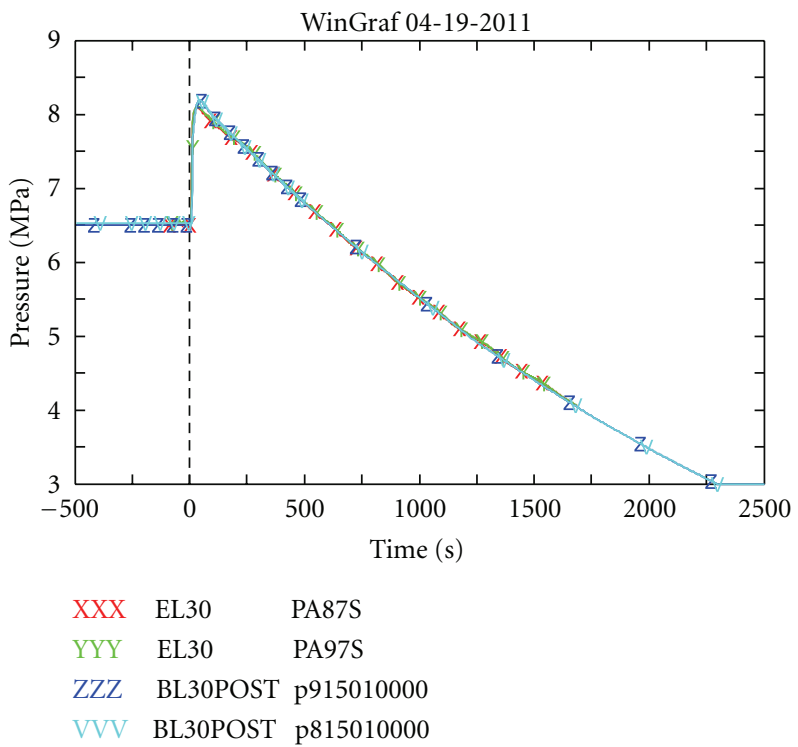

FIGURE 5: Secondary system pressure.

temperatures decrease due to the combined effect of HPIS, loop seal clearing, and accumulator's injection. Since HPISinjected mass is quite similar in experiment and calculation the difference lays in the accumulators injected mass. For the calculation after about $600 \mathrm{~s}$ cladding temperatures are slightly lower than the experiment.

Finally, Figures 9 and 10 show density at the pump inlet zone in the intact and broken loops showing good agreement 


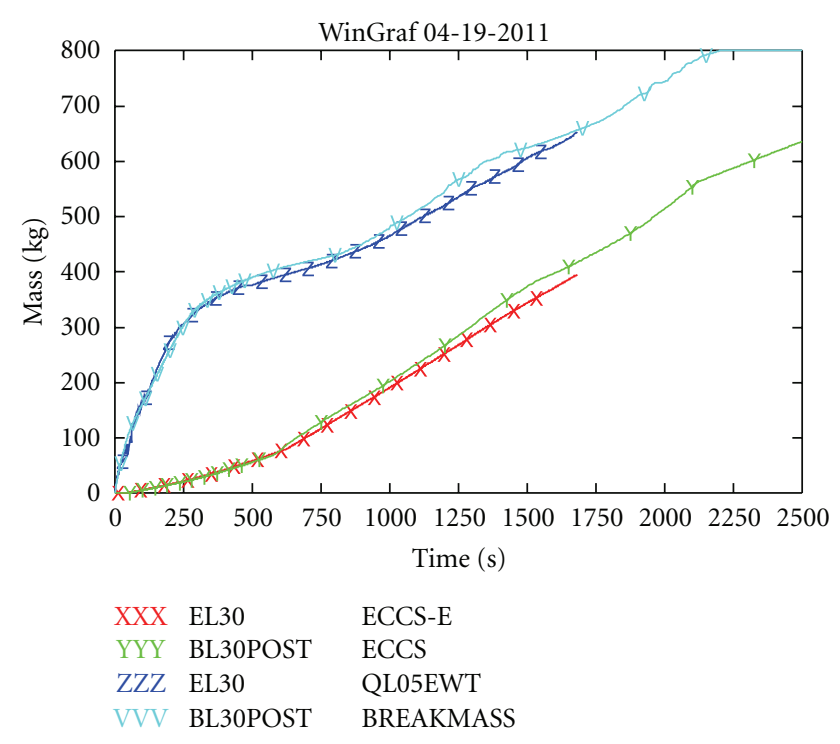

FIGURE 6: ECCS integral mass flow and integral break flow.

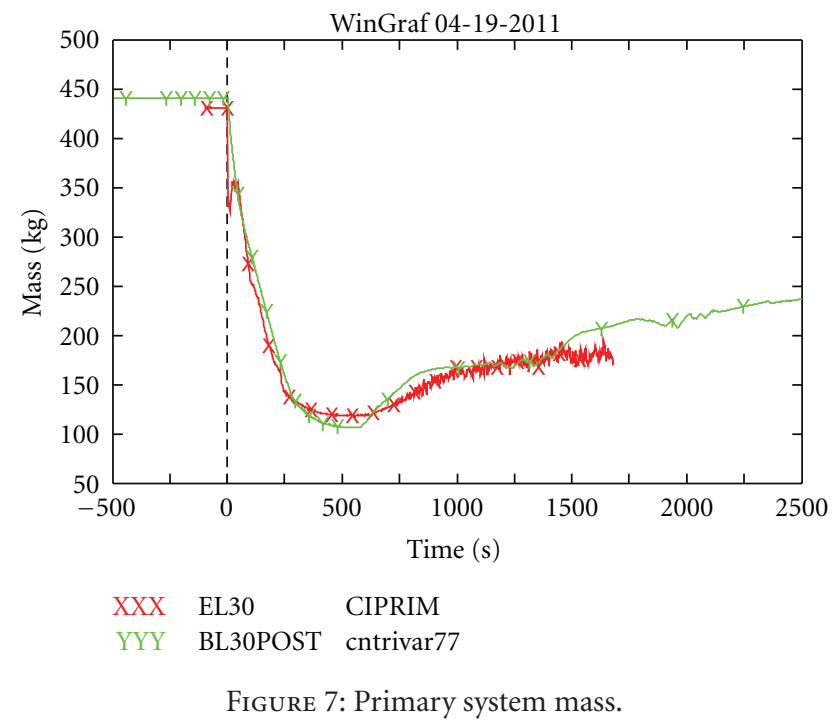

of the calculations with the experimental occurrence of the loop seals clearance.

\section{BL-44 Scenario}

5.1. Experiment Description. The test BL-44 is $6 \%$ a Small Break LOCA originated by a rupture in the cold leg.

For the test BL-44, the LOBI-MOD2 test facility was predisposed in the basic configuration for the cold leg break LOCA experimental.

The sequence of interventions of the various systems is typical of this kind of transient in a plant: after the break occurrence, scram and pumps trips are provided, together with a signal for the isolating steam generators (feed water and steam line closure). Accumulator's intervention is foreseen when primary pressure is below 3.91 MPa. After the accumulator emptying, the flow rate from the break causes
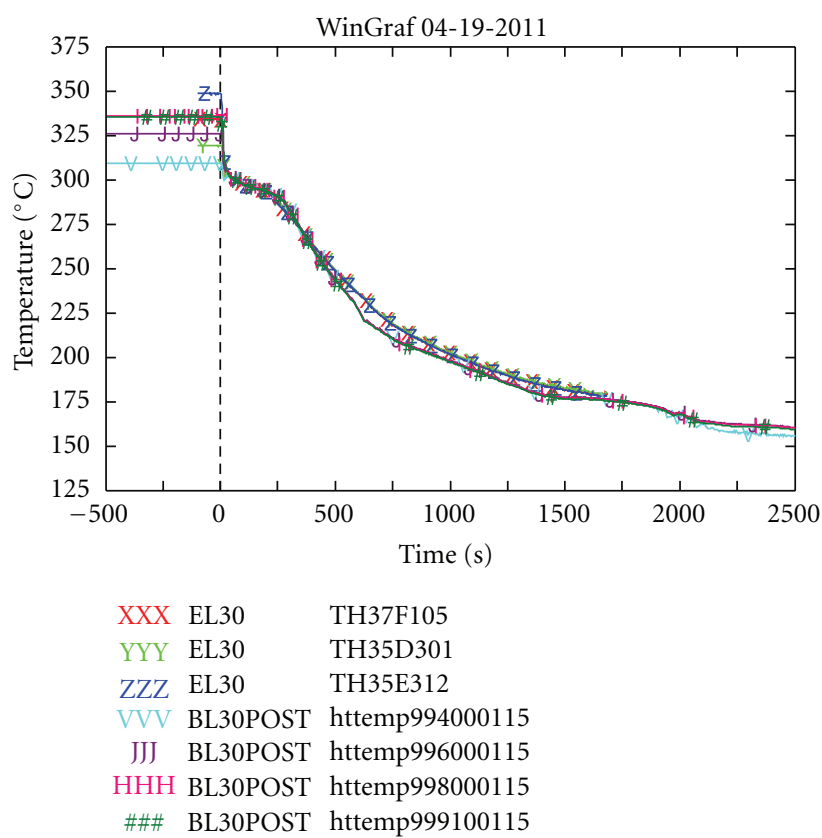

Figure 8: Cladding temperature at different core heights.

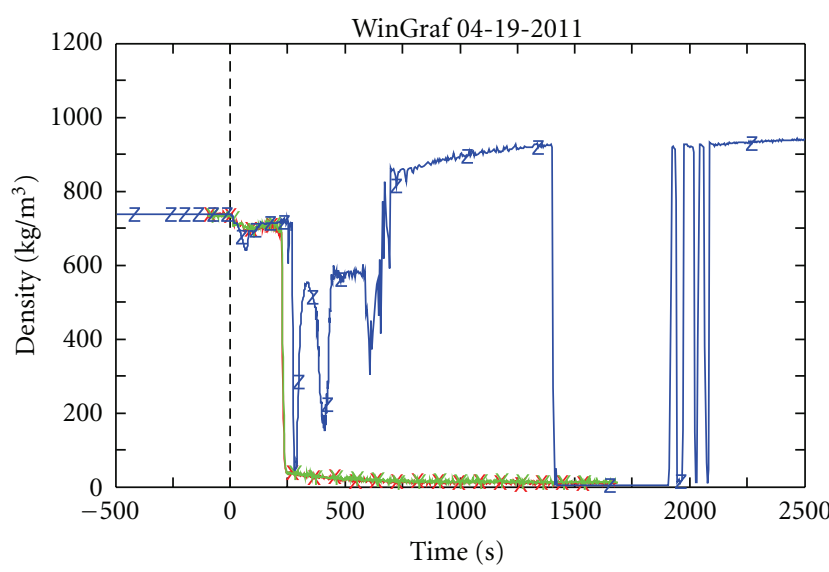

$\begin{array}{lll}\text { XXX } & \text { EL30 } & \text { DD14VDIA } \\ \text { YYY } & \text { EL30 } & \text { DD14VPER } \\ \text { ZZZ } & \text { BL30POST } & \text { rho600010000 }\end{array}$

FIGURE 9: Intact loop seal (pump inlet) density.

mass depletion from the primary side, leading to core dryout. Low-pressure injection system actuation is expected after the occurrence of core dry out and is effective in rewetting the rods.

Main set points of the test BL-44 are shown in Table 3.

Following the break, the primary system started to depressurize up to the achievement of the saturation conditions upstream the break, this occurs at about $80 \mathrm{~s}$ into the transient. The sharp initial pressure decrease lead to scram (at $0.6 \mathrm{~s}$ ), main coolant pump speed reduction (at $0.9 \mathrm{~s}$ ) and isolation of steam generators (at $1.3 \mathrm{~s}$ ). At $5.1 \mathrm{~s}$, the upper plenum and the hot legs reach the saturation condition, and the depressurization rate is largely reduced. The pressurizer 


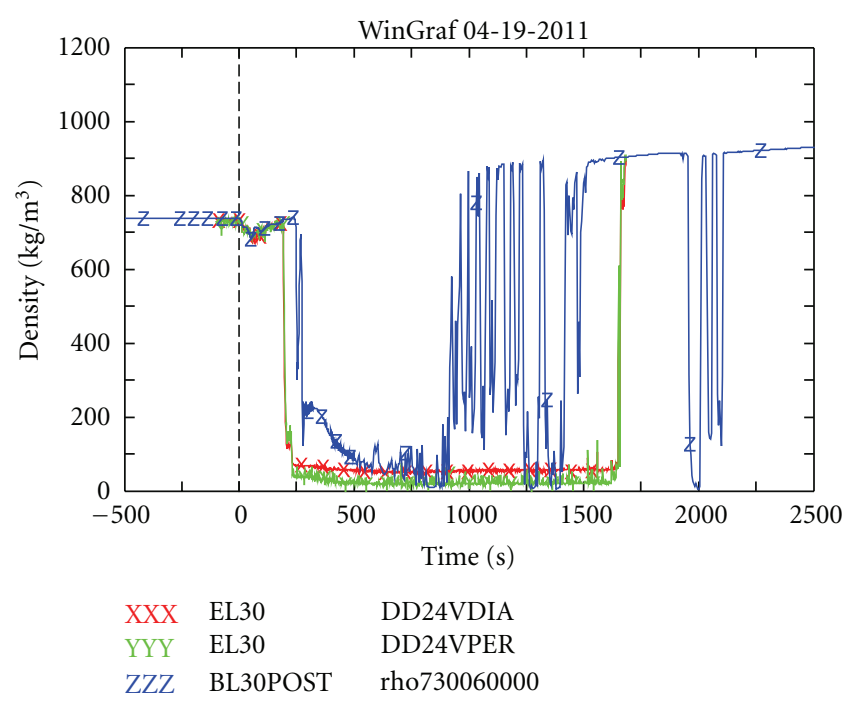

FIGURE 10: Broken loop seal (pump inlet) density.

surge line uncover at about $20 \mathrm{~s}$ determines an increase of the depressurization rate. Pressurizer emptying occurs in about $25 \mathrm{~s}$. During this phase, U-tubes draining occurs in primary side (at about $90 \mathrm{~s}$ ) for the loss of the natural circulation between core and downcomer through the steam generators: at this time, the saturation temperature in the primary loop is still few degrees higher than saturation temperature in the secondary side. The stop in natural circulation, essentially due to voiding and mass depletion in the upper zones of the loop, causes manometers type situation, in the primary loop piping: the steam produced in the core partly flows directly in the break through the bypass and partly pushes over the vessel level and over the IL and BL loop seals. In this situation, core dryout occurs at about $170 \mathrm{~s}$.

At $197 \mathrm{~s}$ loop seal clearing is present in the intact loop.

The core boil off (produced steam flows almost entirely to the break) causes a second dry out at about $351 \mathrm{~s}$ at a pressure near, but higher than the accumulators pressure (3.91 MPa). Probably the reverse speed of the pump (at $-28 \mathrm{rpm}$ during the transient) contributes to the formation of liquid holdup in the broken loop seal, pump side. In this period, the heat transfer from secondary side is quite small compared with core power, because of the high void fraction in the U-tubes.

At $429 \mathrm{~s}$, the primary pressure reached the accumulator setpoint and therefore the accumulator started to inject (in the intact loop, cold leg) a mass flow rate greater than the break flow. The accumulator's intervention causes the recovery of the liquid level in the core and a second rewet that is completed at about $595 \mathrm{~s}$. The accumulator mass flow is stopped at about $971 \mathrm{~s}$ : in the period, from $429 \mathrm{~s}$ to $966 \mathrm{~s}$, the primary system mass increases and the total mass discharged by the accumulator is $135 \mathrm{~kg}$ of water.

The stop of the accumulator's injection, at $970 \mathrm{~s}$, causes another mass depletion period, leading to the third dry out at about $1644 \mathrm{~s}$, when the primary pressure is about $1 \mathrm{MPa}$. In this period, the mixture level in the core drops below the top of heated length. When, at $2073 \mathrm{~s}$, the rod's surface
TABLE 3: Resulting sequence of events, comparison between experimental test and calculated results of BL- 44 .

\begin{tabular}{|c|c|c|}
\hline Events/set-points & $\begin{array}{c}\text { Time after } \\
\text { experiment } \\
\text { initiation (s) }\end{array}$ & $\begin{array}{l}\text { Calculated time } \\
\text { after transient } \\
\text { initiation }(\mathrm{s})\end{array}$ \\
\hline Break opening & 0.0 & 0.0 \\
\hline Scram power curve enabled & 1.4 & 2.6 \\
\hline $\begin{array}{l}\text { Start of the main coolant pumps } \\
\text { coast down }\end{array}$ & 0.9 & 0.0 \\
\hline Main steam line valve closure & - & 3.6 \\
\hline Feedwater valve closure & 1.3 & 2.6 \\
\hline $\begin{array}{l}\text { Upper plenum in saturation } \\
\text { condition }\end{array}$ & 10.0 & 13.0 \\
\hline Pressurizer emptied & 25.0 & 25.0 \\
\hline Break two-phase flow & 117.0 & 115.0 \\
\hline First dry out & 189.0 & - \\
\hline Loop seal clearing_-intact loop & 197.0 & 2250.0 \\
\hline Loop seal clearing_-broken loop & - & 250.0 \\
\hline \multicolumn{3}{|l|}{$\begin{array}{l}\text { Occurrence of minimum primary } \\
\text { side mass }\end{array}$} \\
\hline First & 427.0 & 445.0 \\
\hline Second & 2071.0 & 2070.0 \\
\hline $\begin{array}{l}\text { Primary-secondary pressure } \\
\text { reversal }\end{array}$ & 208.0 & 212.0 \\
\hline Second dry out & 372.0 & 420.0 \\
\hline Accumulator injection starts & 429.0 & 439.0 \\
\hline Accumulator injection stops & 970.0 & 1065.0 \\
\hline Rewetting due to accumulator & 547.0 & 525.0 \\
\hline Final dry out & 1711.0 & 1795.0 \\
\hline LPIS start & 2065.0 & 2073.0 \\
\hline Final rewetting & 2203.0 & 2207.0 \\
\hline End of the test & 2400.0 & 3000.0 \\
\hline
\end{tabular}

temperature reaches $772 \mathrm{~K}$ the low-pressure injection system is actuated (2073 s) in the intact loop cold leg; at this time, the pressure is about $0.73 \mathrm{MPa}$.

The LPIS flow rate $(0.4 \mathrm{~kg} / \mathrm{s})$ is effective in causing the third core quench and in recovering the facility. The quench front velocity is larger than $0.02 \mathrm{~m} / \mathrm{s}$ and, at $2173 \mathrm{~s}$ the core is completely recovered. Core refill occurs in this period. The test was terminated at $2400 \mathrm{~s}$ with a pressure of $0.55 \mathrm{MPa}$.

Figure 11 shows a snapshot of a video of the experimental real-time collapsed levels and plots of primary and secondary pressures.

5.2. Posttest Calculation. The input deck [18] is chosen on the basis of the agreement between the trends of the calculation and experimental parameters and also taking into account that in the simulation the initial and boundary conditions of the experiment are preserved. In Table 3 are shown the sequence of the main events and the set points for the calculation compared to the BL-44 experiment. The agreement is quite close. A comment loop seal clearing follows below. 


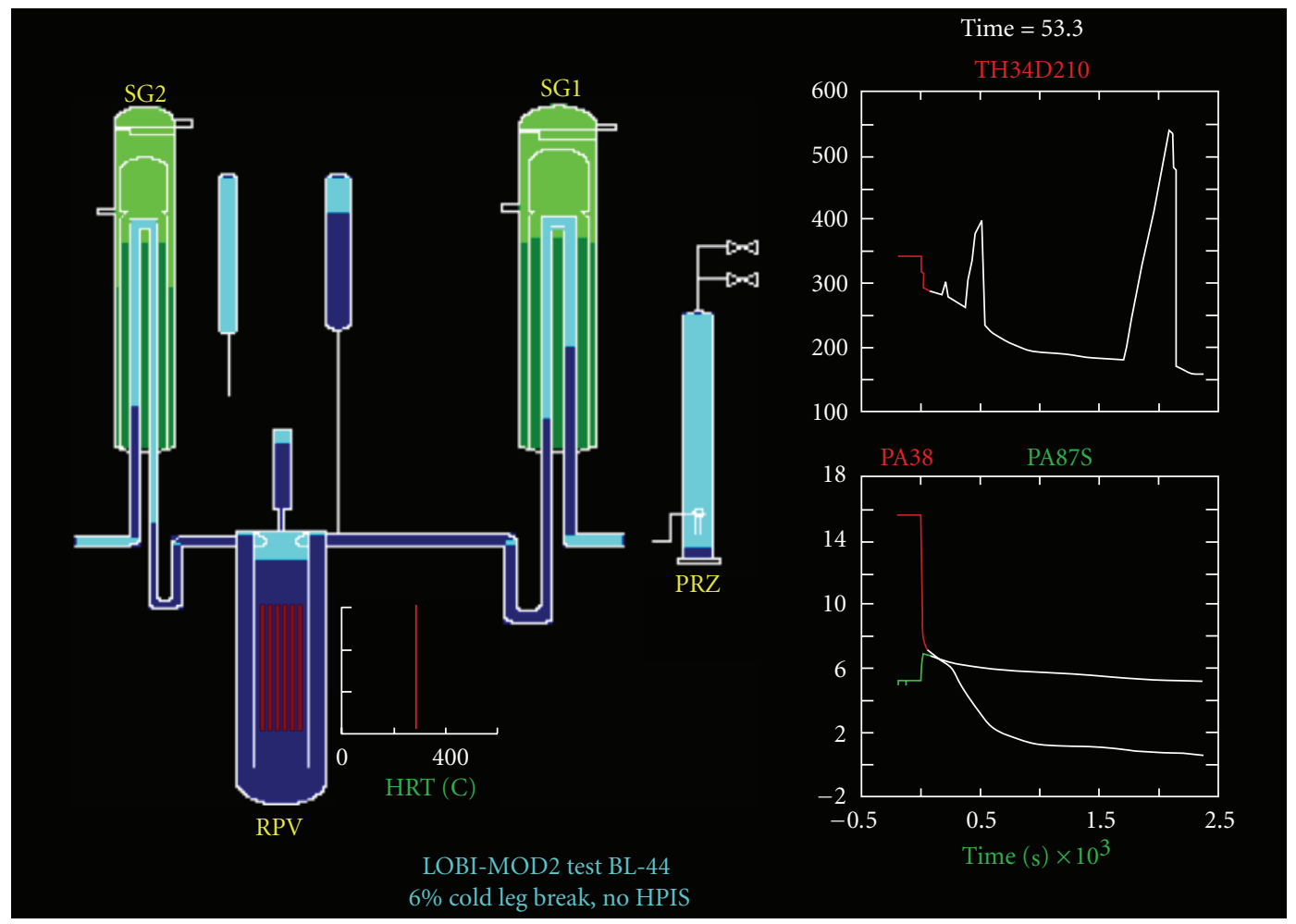

FIGURE 11: BL-44 experiment collapsed levels display and primary and secondary pressures (STRESA JRC database).

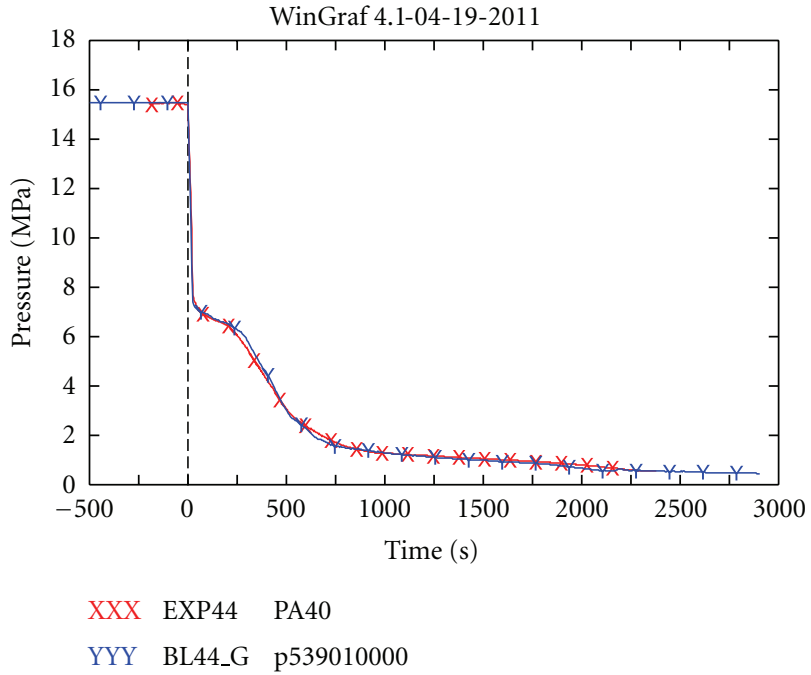

Figure 12: Primary system pressure.

In the following figures are shown the results of BL-44 experiment calculation (descriptor BL44_G), compared with the experimental data (descriptor EXP44).

The primary system pressure is well predicted by the code and the phenomenological phases (e.g., subcooled blowdown, saturated blowdown, and steam flow from the break) can be easily recognized from the calculated time trend, as shown in Figure 12.

Loop seal clearing is a very sensitive phenomenon. In BL-44 test, both loop seals were about to be cleared by

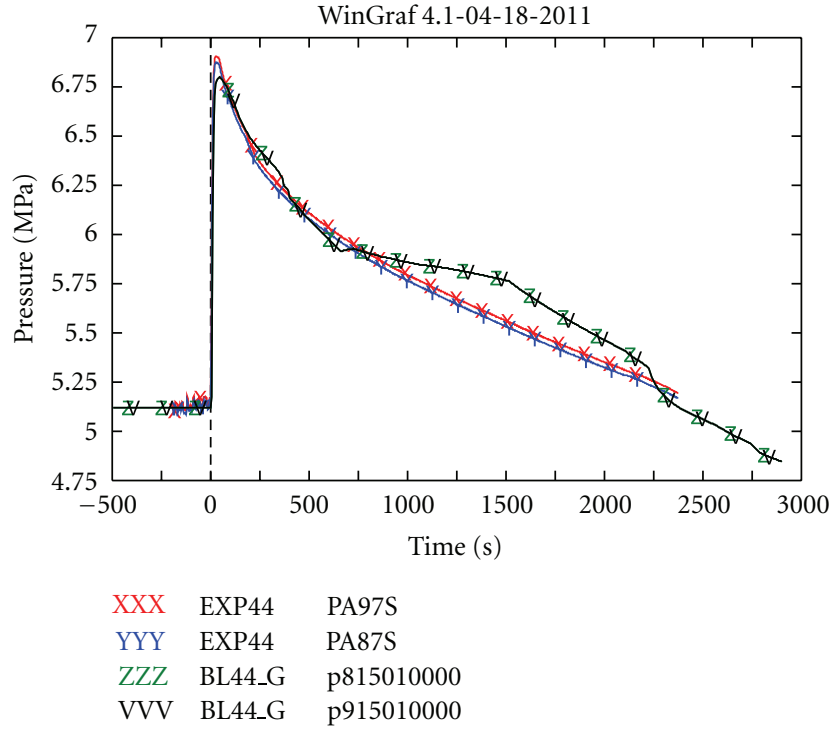

FIGURE 13: Secondary system pressure.

the end of two-phase flow discharge. Once one loop seal is effectively cleared, differential pressures change completely and the other loop seal remains uncleared for quite a long time. While in the test, intact loop seal is effectively cleared, in the simulation this happens with broken loop.

Figure 13 shows that the secondary system pressure, in the intact loop (vols. 97, 815) and in the broken loop (vols. 87,915 ), is in quite good agreement with the experimental 


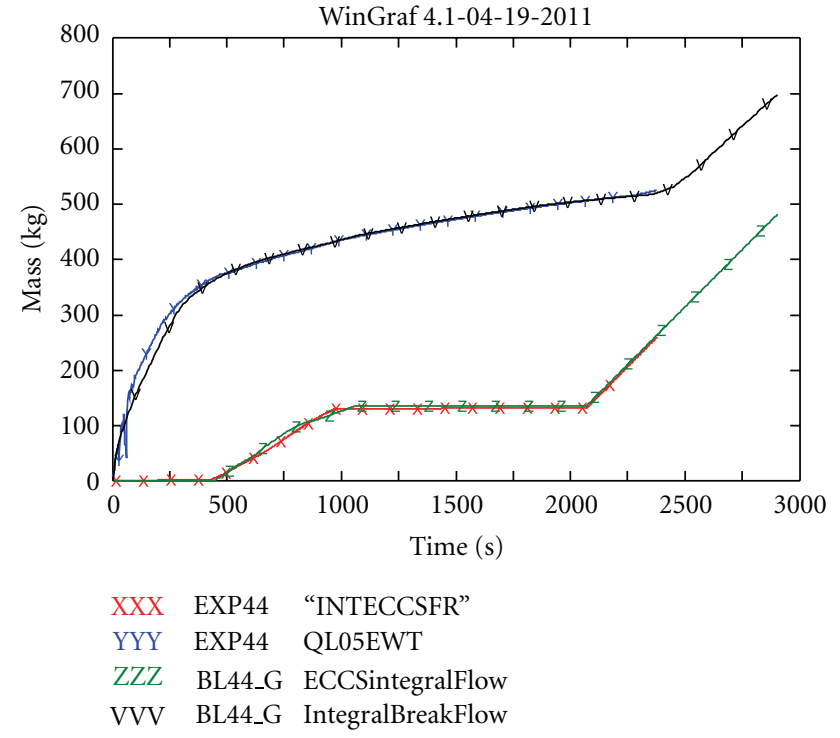

Figure 14: ECCS integral mass flow and integral break flow.

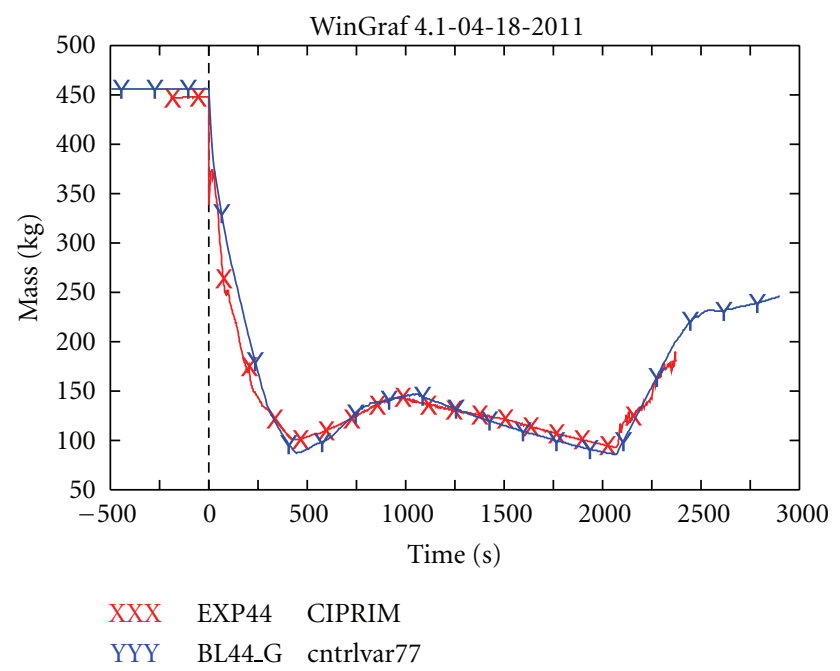

Figure 15: Primary system mass.

trend. The calculated pressure is slightly underestimated in the first part of the transient (before $700 \mathrm{~s}$ ) and overestimated in the final part of the transient (after $700 \mathrm{~s}$ ). Since in this test, the secondary side is isolated and no cooldown is carried out, its behavior is very sensitive. Secondary pressure depends in this case on two quite small heat extractions: heat transfer from secondary to primary side and heat losses to environment. Both aspects were studied performing sensitivity calculations. Setting the right time of closure of the feedwater helped the simulation but that of the steam lines was not available and a standard value was used. Heat losses were also studied in relation the other two tests. This will be commented in the last section.

ECCS (accumulator mass injected and LPIS mass flow) and integral break mass are shown in Figure 14. Accumulator starts to inject when primary pressure below $3.91 \mathrm{MPa}$ (at

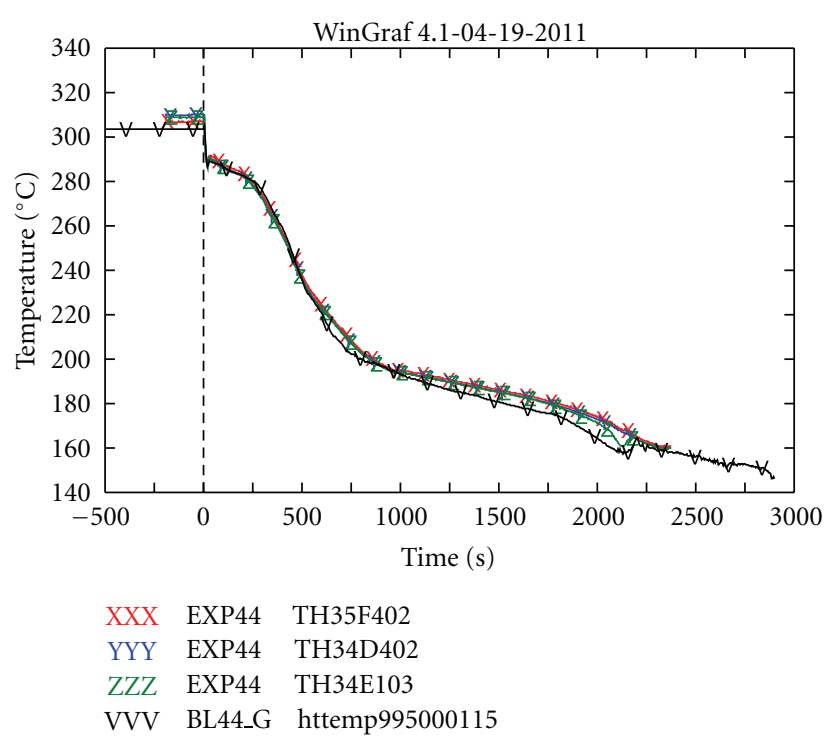

Figure 16: Cladding temperature at bottom level.

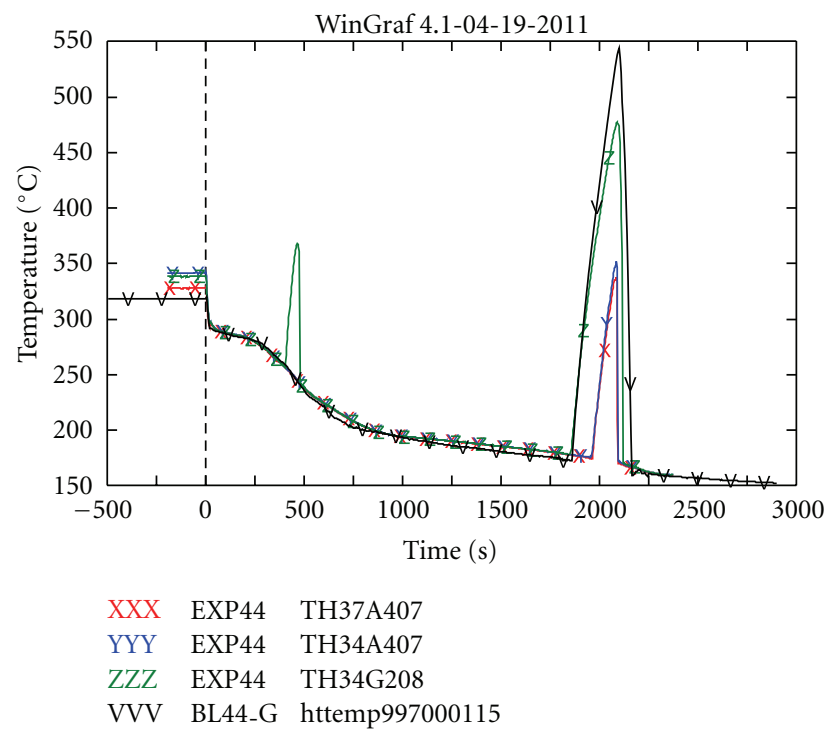

Figure 17: Cladding temperature at middle level.

about 439 s), the LPIS starts to inject when the rods surface temperature reaches $772 \mathrm{~K}$, at $2073 \mathrm{~s}$. The trends of ECCS and integral break mass flow are well predicted.

The primary system mass is shown in Figure 15, after the break PS mass decrease, then, with the accumulator and LPIS injection, the PS mass start to increase.

Representative experimental data at three core levels (bottom, middle, high region), in the axial direction, have been selected for the comparison with the calculated data (Figures 16, 17, and 18). Calculated rod surface temperature trends follow well the measured values. The first dryout is not predicted by the code. The second and the third dry out situation are well predicted. 


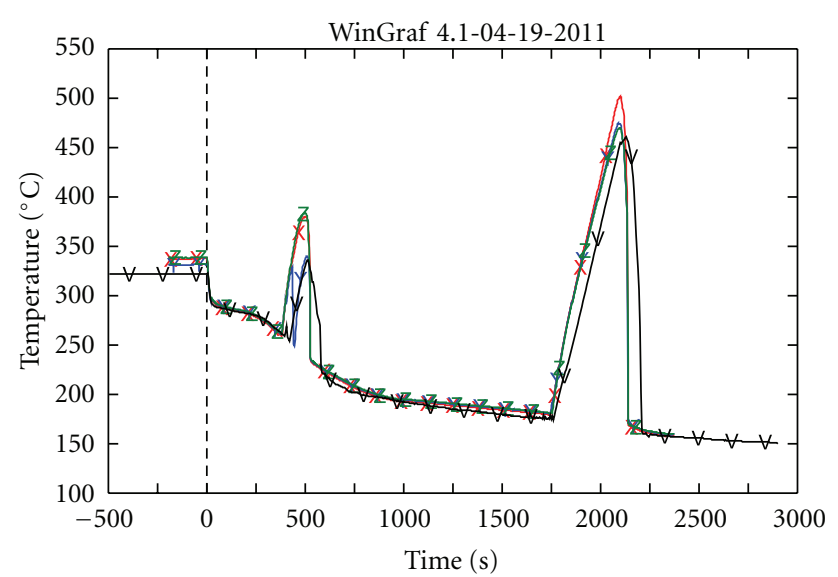

XXX EXP44 TH37F209

YYY EXP44 TH38C209

ZZZ EXP44 TH31G209

VVV BL44-G httemp999100115

FIGURE 18: Cladding temperature at high level.

\section{A1-84 Scenario}

6.1. Experiment Description. Test A1-84 simulates a 10\% hot leg break (break orifice diameter $=9.5 \mathrm{~mm}$, side oriented) in the main coolant pipe of a PWR. Cooldown is applied to the secondary side at a rate of $100 \mathrm{~K} / \mathrm{h}$. Emergency core cooling water is injected into the primary loops by the Accumulators and the HPIS. The Accumulators are connected to both legs of the intact loop and to the cold leg of the broken loop. The high pressure injection system is connected to the hot leg of the intact loop. The injection rate is representative of two injection pumps (out of four). The remaining two pumps (that exist in the reference plant) are assumed to be one in maintenance and the other connected to the broken loop.

Boundary conditions during the test follow the behavior of the reference plant after leak detection.

Within $1 \mathrm{~s}$ after rupture, the primary system depressurizes to $132 \mathrm{bar}$, and this enables the core heating power and the secondary system cooldown signals. The isolation procedure (closure of feedwater valves and main steam valve at condenser inlet) together with the automatic cooldown $(100 \mathrm{~K} / \mathrm{h})$ of the secondary system are actually initiated at $1.3 \mathrm{~s}$ after the rupture, and this causes a delay in the primary and secondary pressures responses.

Saturation pressure in hot leg is reached at about $2 \mathrm{~s}$; the attainment of this pressure brings to a moderate change in primary system depressurization, which continues at a reduced rate as the fluid, in the upper vessel internals, started to flash.

At $5 \mathrm{~s}$ into the transient, the HPIS pressure set point (117 bar) is reached, but the high pressure emergency core cooling system initiates with a delay of $35 \mathrm{~s}$, at about $40.6 \mathrm{~s}$.

At $7 \mathrm{~s}$, coastdown of the main coolant pump starts, upon actuation, at $6 \mathrm{~s}$, at the 110 bar low primary system pressure set point.
As the primary mass inventory lowers because of the outflow from the break, the pressurizer surge line eventually uncovers at about $17.5 \mathrm{~s}$.

At $23 \mathrm{~s}$ the saturation front reaches the cold leg elevation and at $42 \mathrm{~s}$ the whole primary system achieves saturation condition as the system depressurizes to the saturation pressure of the fluid in the lower plenum.

At about $84 \mathrm{~s}$ into the transient the primary pressure falls below the secondary one, giving rise to potential reverse heat transfer in the steam generator.

After the uncovering of the break, at about $150 \mathrm{~s}$, the primary cooling system depressurizes faster and soon reaches the pressure setpoint for the accumulators' actuation $(2.8 \mathrm{MPa})$.

Within $850 \mathrm{~s}$ the system has a pressure of $1 \mathrm{MPa}$, which is the pressure set-point for test termination.

Figure 19 shows a snapshot of a video of the experimental real-time collapsed levels and plots of primary and secondary pressures.

6.2. Posttest Calculation. The input deck [19] is chosen on the basis of the agreement between the trends of the calculation and experimental parameters and also taking into account that in the simulation the initial and boundary conditions of the experiment are preserved.

The sequence of main events which characterize the course of the transient is shown in Table 4. The agreement is quite close.

The results obtained from A1-84 test simulation (descriptor A1-84-11.0) are plotted and described below, in comparison with the experimental data available (descriptor EX84).

In Figure 20, the PS pressure is shown; the prediction is in close agreement with the experiment, the depressurization rate is well reproduced, and it is clearly highlighted that the moment in which saturation in the primary side is reached because there is an important decrease in the curve slope.

Figure 21 shows SS steam dome pressure in the broken loop (vols. 87, 915) and in the intact loop (vols. 97, 815) for A1-84 experiment and RELAP5 Mod 3.3 simulation. The secondary pressure behavior is very well simulated, and the cooldown $(100 \mathrm{~K} / \mathrm{h})$ is correctly implemented.

Figures 22, 23, and 24 show the ECCS mass flow rate (HPIS mass flow and integral flow, accumulators' levels) together with the integral mass flow flowing out of the break. HPIS is actuated after $40 \mathrm{~s}$ in the code calculation and in the experiment. The mass flow rate injected depends on the primary system pressure. The code simulation perfectly matches the experiment. The accumulators start to inject at about $350 \mathrm{~s}$, but the BL injection is stopped at about $560 \mathrm{~s}$, and the IL accumulator injection is never stopped. The accumulator levels shows an acceptable trend if compared to the experimental (Figure 23).

Moreover the simulated integral mass flow through the break (Figure 24) is in agreement with the corresponding time trend derived from experimental data.

Figure 25 shows PS total mass inventory: it decreases after the break, reaching a minimum at $350.0 \mathrm{~s}$ and starts to recover due to HPIS and accumulators injections. 


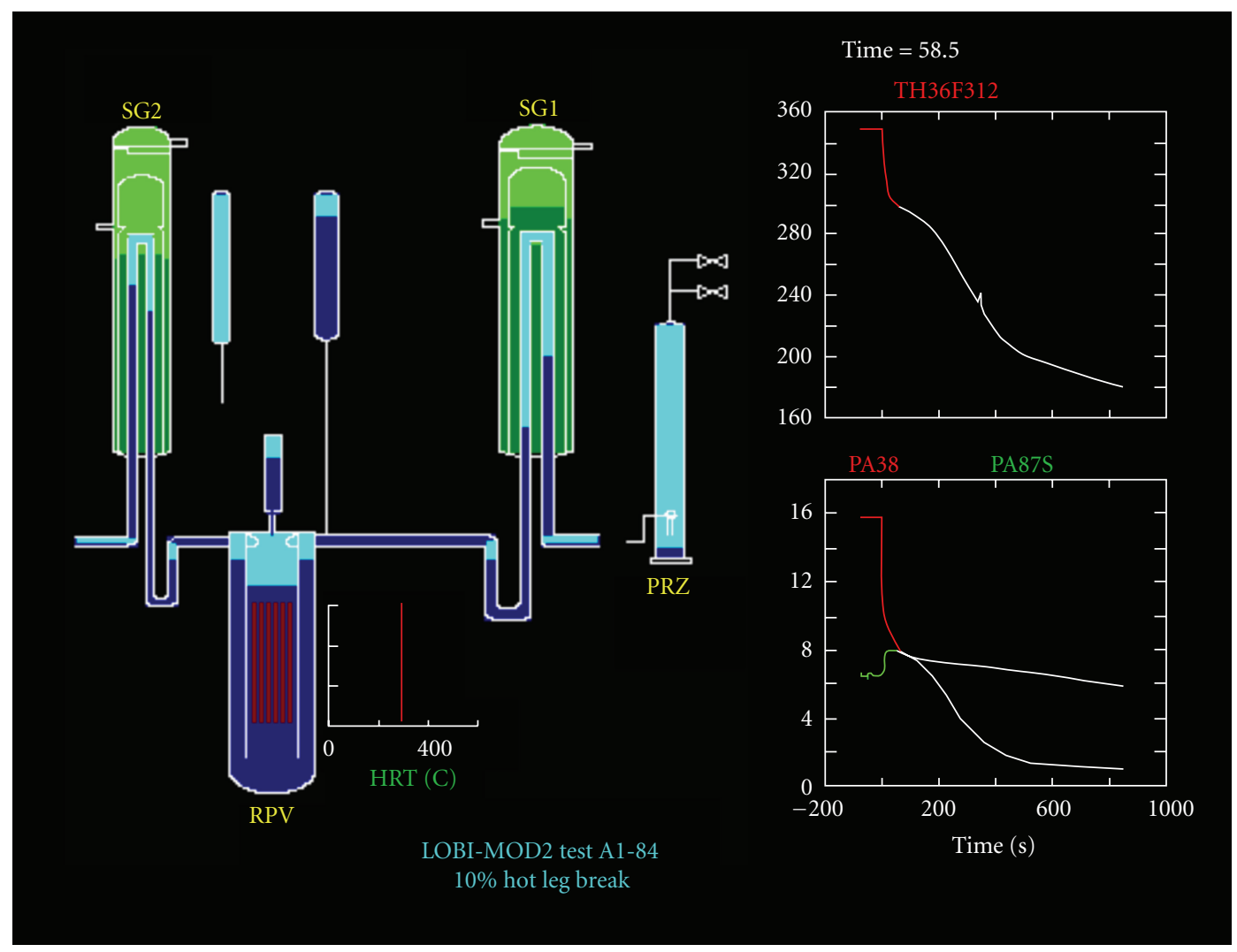

FIGURE 19: A1-84 experiment collapsed levels display and primary and secondary pressures (STRESA JRC database).

TABLE 4: Resulting sequence of events, comparison between experimental test and calculated results of A1-84.

Events/set points Time after experiment initiation (s) Calculated time after transient initiation (s)

Break opening 0.0 0.0

SCRAM signal (at $13.2 \mathrm{MPa}+$ delay $0.5 \mathrm{~s}$ )

1.0

1.3

$1.5 \mathrm{~s}$ valve closure time)

Pressure in PS 11.7 MPa

MCPs start coastdown (at 11.0 MPa + delay $1.0 \mathrm{~s}$ )

Upper plenum in saturation conditions

HPIS actuation (at 11.7 MPa + delay $35 \mathrm{~s}$ )

PS pressure falls below SS pressure IL/BL

Occurrence of minimum primary side mass

Accumulator actuation IL/BL (at $2.8 \mathrm{MPa}$, disabled at $11 \mathrm{Mpa}+$ delay $500 \mathrm{~s}$ in cold leg, not disabled in hot leg)

Auxiliary feedwater in broken loop

Accumulator injection stops Cold leg IL/BL

Accumulator injection stops Hot leg IL

End of the test $(0.1 \mathrm{Mpa})$

\section{0}

7.0

15.8

40.0

$90.8 / 97.8$

347.4

$347.0 / 349.9$

$509.0 / 520.0$

849.0

850.0
1.0

13.0 (imposed by time)

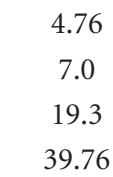

$101.3 / 101.83$

350.0

$335.1 / 335.0$

487.4/558.7

849.0

850.0
Figure 26 shows fuel cladding temperatures at middleheated length height, in the core region: no dry-out is observed and temperatures decrease because of the combined injection of HPIS and accumulators. No loop seal clearing is observed, according to what happens in the experiment.
The temperature trend is well matched, with the exception of the second half of transient, when the calculated results slightly underestimate the experimental data.

Figure 27 shows the pressure drop along the vessel, from the inlet of the downcomer, to the outlet of the vessel (hot leg inlet). The trend is well reproduced by the code during 

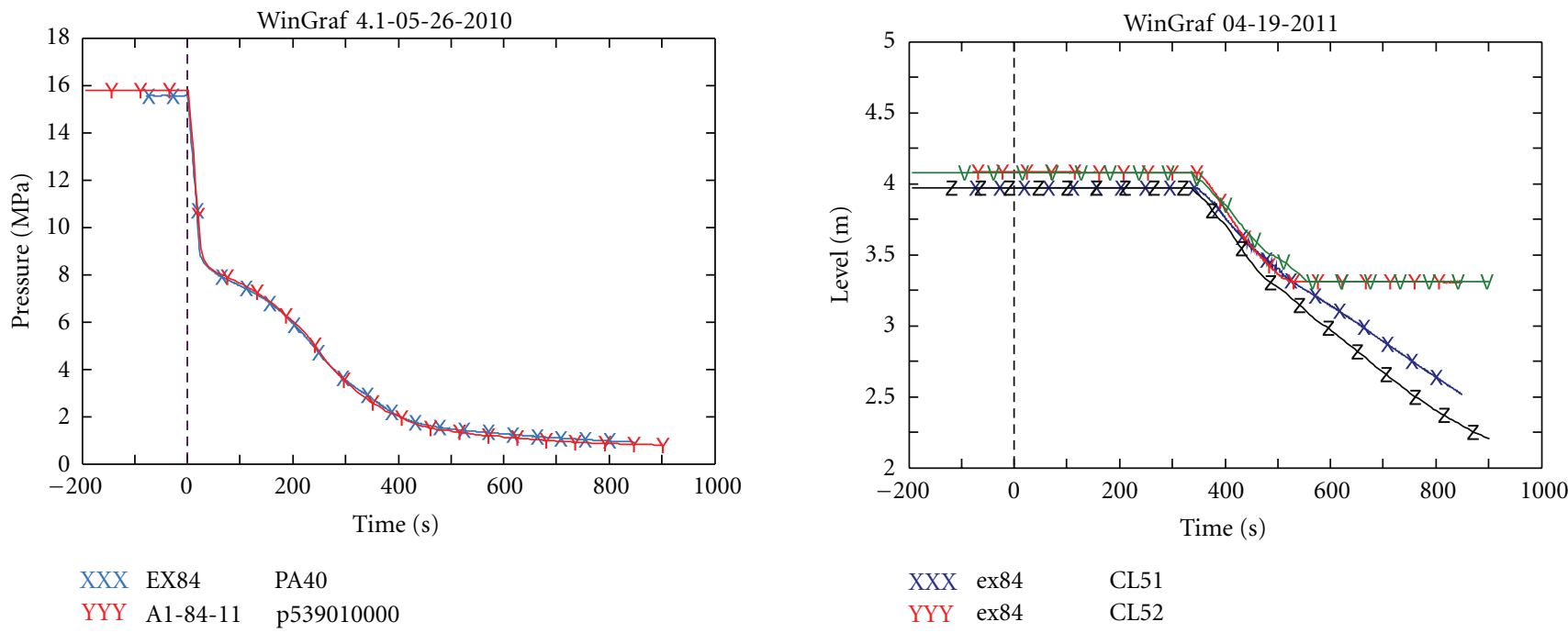

Figure 20: Primary system pressure.
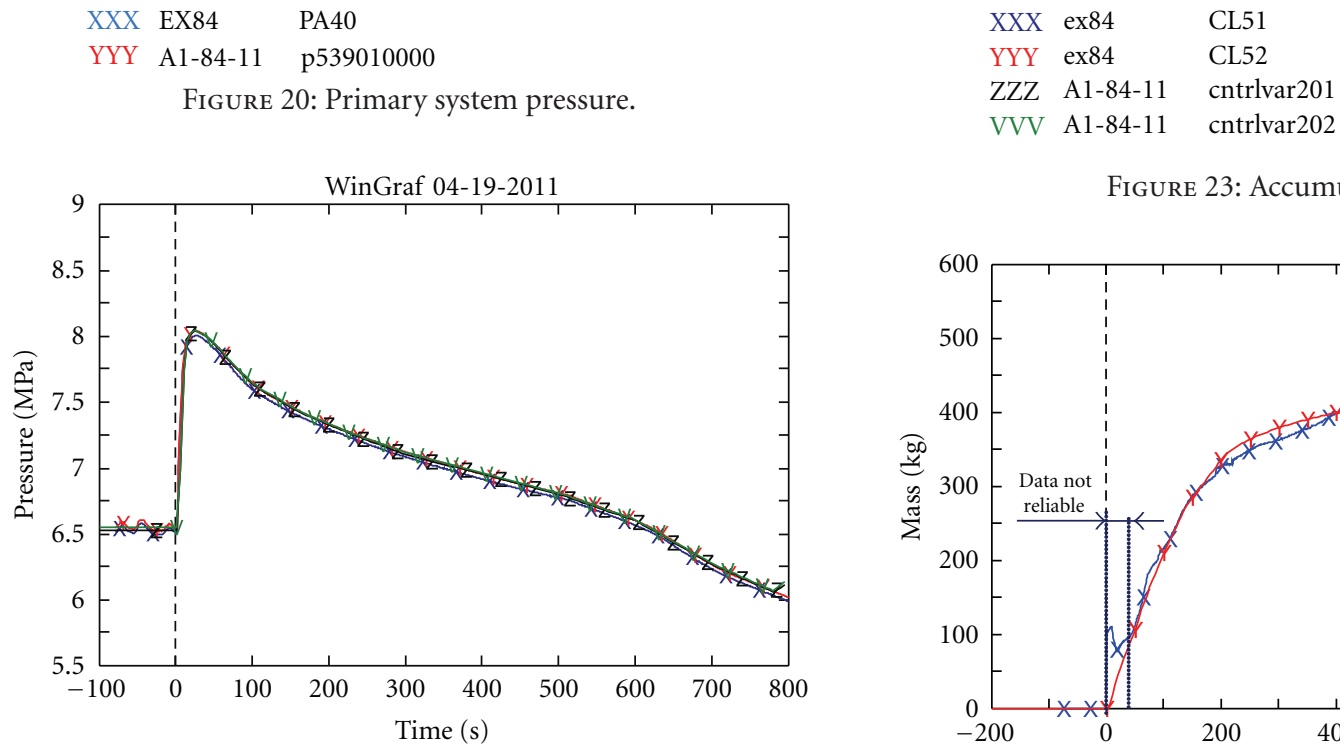

Figure 23: Accumulators levels.

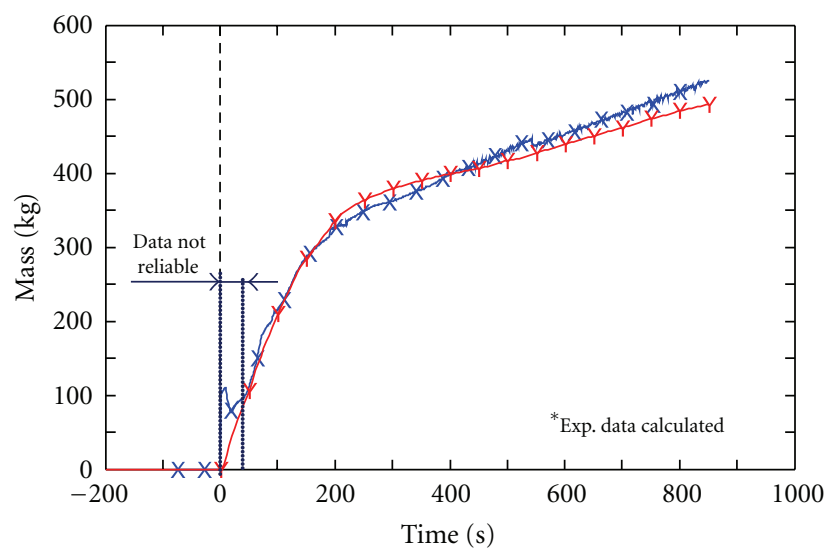

$\begin{array}{lll}X X X & \text { ex84 PA87S }\end{array}$

YYY $\quad$ ex84 PA97S

ZZZ A1-84-11 p915010000

VVV A1-84-11 p815010000

Figure 21: Secondary system pressure.

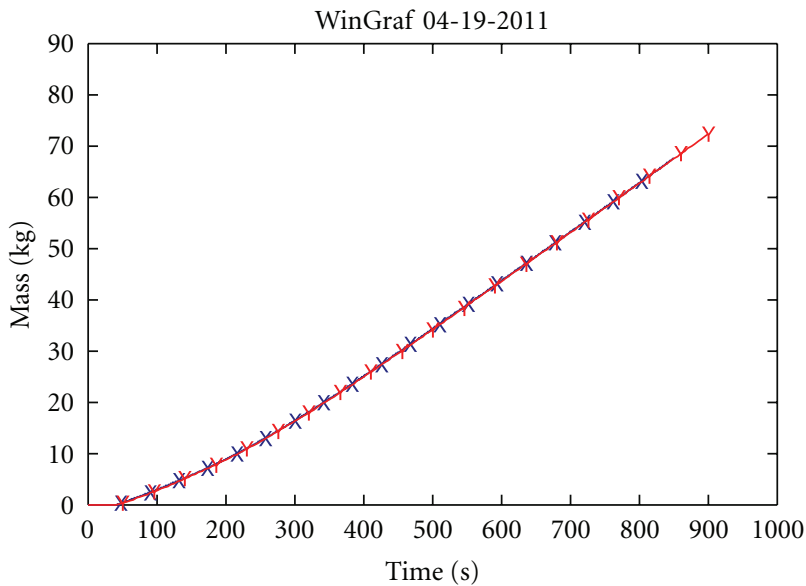

XXX EX84 IntegralFLHPISex84

YYY EX84 IntegralFlowrateHPIS

FIGURE 22: HPIS integral mass flow.

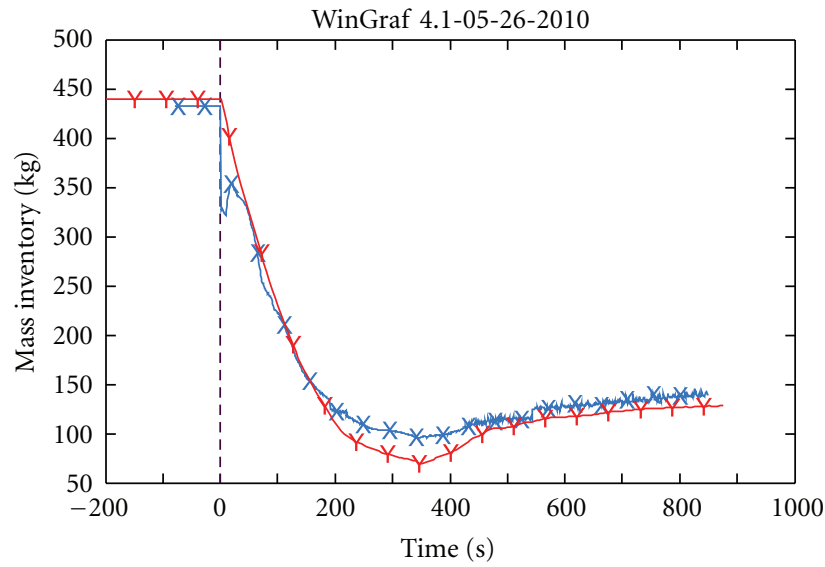

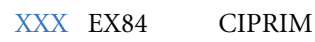

YYY A1-84-11 cntrlvar77

FIgURe 25: Primary system mass. 

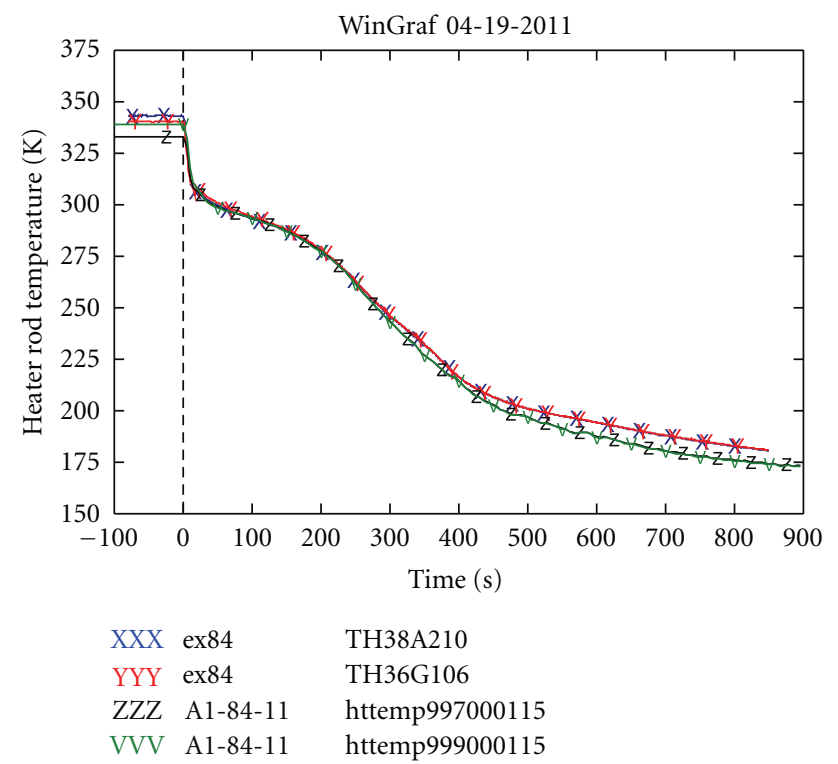

Figure 26: Cladding temperature, middle- and top-heated length level.

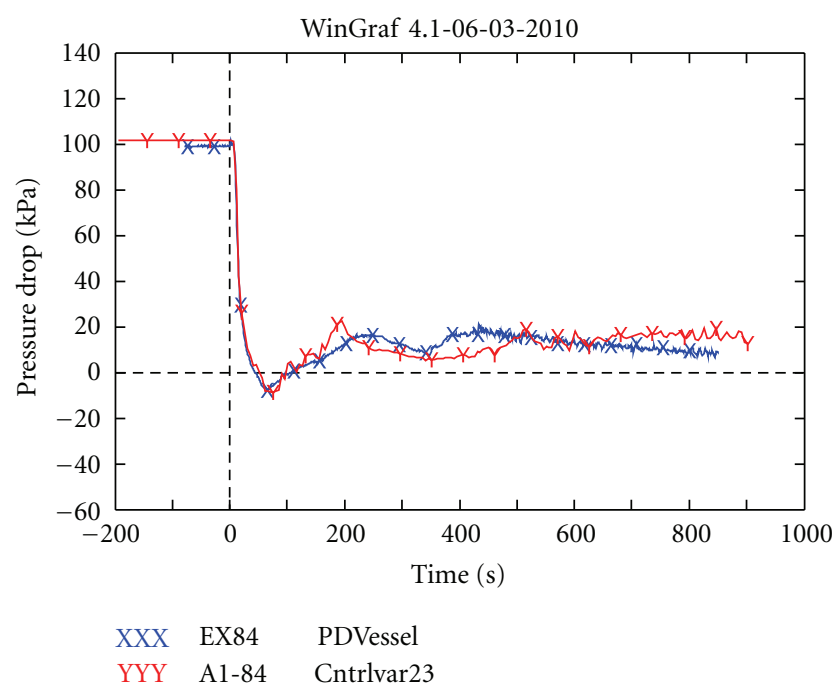

FIGURE 27: Vessel pressure drop.

steady state and the beginning of the transient demonstrating that the RELAP5 model was correctly setup. Once the MCP are stopped reasonable prediction implies that reasonable mass distribution in the vessel is achieved (considering the primary pressure and coolant temperature are correctly predicted).

\section{Discussion and Conclusions}

Posttest calculations of LOBI tests BL-30, BL-44, and A184 have been carried out successfully. The results are in close agreement with experimental data and will become an interesting starting point for both future scaling calculations and accuracy evaluations.

The three tests have been simulated using the same LOBI facility nodalization. The procedure to come up with the final version of the common nodalization involved some iteration. Once a clear improvement of the predictions was obtained for one test by means of a nodalization change, the other tests were recalculated and following the quality the new results the suggested change was accepted and confirmed.

All posttests show good predictions for primary system mass time trends. The final set of values corresponding to hydrodynamic loss coefficients on primary side are exactly the same for the three tests. These final values were carefully chosen taking into account the results of preliminary calculations (mainly delta-p and mass inventory), and they have been confirmed after recalculating all tests.

By-pass paths through vessel upper head and also the general lay-out it, are quite complex, but general geometry is about the same for all the involved tests. Hydrodynamic loss coefficients, as well as interconnecting areas between upperhead volumes follow a similar consolidating practice.

Heat losses to environment are only sensitive in tests or phases of tests in which they become comparable to other heat extractions. In this case, heat loss coefficients were reasonable adjusted for BL-44 (in the time window where heat losses were comparable to other heat extractions) and the adjusted value was used for the other two tests, where the secondary side cooldown was the dominant effect which completely shadows environment impact.

This mutual consistency among the presented calculations is a relevant point that adds value to the results and confirms the procedure of implementing changes in a common nodalization valid for simulating tests occurred in a specific ITF.

The outcome of the presented analysis will be helpful to support the involved steps of integral plant model qualification procedures and uncertainty evaluation methodologies.

\section{Acronyms}

AFW: $\quad$ Auxiliary feedwater of SGs

BE: $\quad$ Best estimate

CIAU: Code with the capability of internal

assessment of uncertainty

EC: $\quad$ European commission

ECCS: Emergency core cooling

FW: $\quad$ Main feedwater of SGs

HPIS: High-pressure injection system

ITF: Integral test facility

JRC: Joint research centre

KWU: Kraftwerk Union

LB LOCA: Large break loss of coolant accident

LOBI: LWR off-normal behaviour investigations

LPIS: $\quad$ Low pressure injection system

LWR: Light water reactor

MCP: $\quad$ Main coolant pump

NPP: $\quad$ Nuclear power plant

PCT: $\quad$ Peak cladding temperature

PS: $\quad$ Primary system

PWR: Pressurized water reactor

SB LOCA: Small break loss of coolant accident

SG: $\quad$ Steam generators

SRV: $\quad$ Steam relief valve 
SS: $\quad$ Secondary system

STRESA: Storage of thermal reactor safety analysis data

UNIPI: University of Pisa

UPC: Universitat Politècnica de Catalunya, Technical University of Catalonia

UP: $\quad$ Upper plenum.

\section{Acknowledgments}

The authors would like to thank Giorgio Galassi, from the GRNSPG-UNIPI, and Alessandro Annunziato, and Carmelo Addabbo, from the JRC Ispra, for their constructive discussions, explanations, and help during all the posttest analysis period regarding the modeling and the LOBI facility hardware details. From JRC of Petten, authors are grateful also to Manuel Martin Ramos for his constructive discussions during the BL-30 posttest activity and to Marcello Barboni for the informatics support related to the STRESA Database.

\section{References}

[1] V. M. Martínez, F. Reventós, C. Pretel, and I. Sol, Code Validation and Scaling of the ROSA/LSTF Test 3-1 Experiment, European Nuclear Society, Dubrovnik, Croatia, 2008.

[2] F. D'Auria, N. Debrecin, and G. M. Galassi, "Outline of the uncertainty methodology based on accuracy extrapolation," Nuclear Technology, vol. 109, no. 1, pp. 21-38, 1994, OECDCSNI Special Workshop on Uncertainty Analysis Methods, London (UK).

[3] F. Reventós, L. Batet, C. Llopis, C. Pretel, M. Salvat, and I. Sol, "Advanced qualification process of ANAV NPP integral dynamic models for supporting plant operation and control," Nuclear Engineering and Design, vol. 237, no. 1, pp. 54-63, 2007.

[4] C. Addabbo and A. Annunziato, "The LOBI test matrixLOBI project, "STRESA database web platform.

[5] "JRC STRESA database web platform, "http://stresa.jrc.ec. europa.eu/stresa/.

[6] A. Annunziato, "Quick look report on LOBI-MOD2 test BL30 (5\% Cold Leg Break LOCA),” Tech. Rep., Joint Research Centre, Ispra, Italy, 1990.

[7] J. Sanders and E. Ohlmer, "Experimental data report on LOBIMOD2 test BL-30 (5\% Cold Leg Break LOCA)," Tech. Rep., Joint Research Centre, Ispra, Italy, 1990.

[8] A. Annunziato, "Quick look report on LOBI-MOD2 test BL44 (6\% Cold Leg Break LOCA),” Tech. Rep., Joint Research Centre, Ispra, Italy, 1992.

[9] C. Addabbo, G. Leva, and A. Annunziato, "Experimental data report on LOBI-MOD2 test BL-44 (6\% Cold Leg Break LOCA)," Tech. Rep., Joint Research Centre, Ispra, Italy, 1992.

[10] C. Addabbo, R. Wampach, and G. Leva, "Quick look report on LOBI-MOD2 test A1-84 (10\% Hot Leg Break LOCA),” Tech. Rep., Joint Research Centre, Ispra, Italy, 1986.

[11] J. Sanders and E. Ohlmer, "Experimental data report on LOBIMOD2 test A1-84 (10\% Hot Leg Break LOCA)," Tech. Rep., Joint Research Centre, Ispra, Italy, 1986.

[12] A. Berthon, Caracterización de la evaluación de seguridad del reactor WWER-1000 mediante metodología "Best Estimate" con análisis de incertidumbres, M.S. thesis, University of Pisa, Italy, 2005.
[13] F. D'Auria, M. Frogheri, and W. Giannotti, RELAP5/MOD3.2 Post Test Analysis and Accuracy Quantification of LOBI Test BL44;NUREG/IA-0153, University of Pisa, Italy, 1999.

[14] F. D'Auria and W. Giannotti, "Development of a code with the capability of internal assessment of uncertainty," Nuclear Technology, vol. 131, no. 2, pp. 159-196, 2000, CAMP Meeting, Bariloche, Argentina, 1999 (invited paper), Relap5 International Users Seminar, Park City (Utah, USA), 1999.

[15] C. Pretel and F. Reventós, "Post-test analysis of LOBI test BL-30 using RELAP5/MOD2.5,” Tech. Rep. I.93.64, Technical University of Catalonia, Asociación Nuclear Ascó, Spain, 1993.

[16] B. Worth and H. Staedtke, "Relap5 base input data for LOBIMOD2,” Tech. Rep., Joint Research Centre, Ispra, Italy, 1985.

[17] U. S. Nuclear Regulatory Commission, RELAP5/MOD3.3 Code Manual, vol. 4, U. S. Nuclear Regulatory Commission, Idaho Falls, Idaho, USA, 2001.

[18] G. Nacci, Post-test analysis of BL-44, M.S. thesis, University of Pisa, Italy, 2011.

[19] C. Matteoli, Post-test analysis of A1-84, M.S. thesis, University of Pisa, Italy, 2011. 

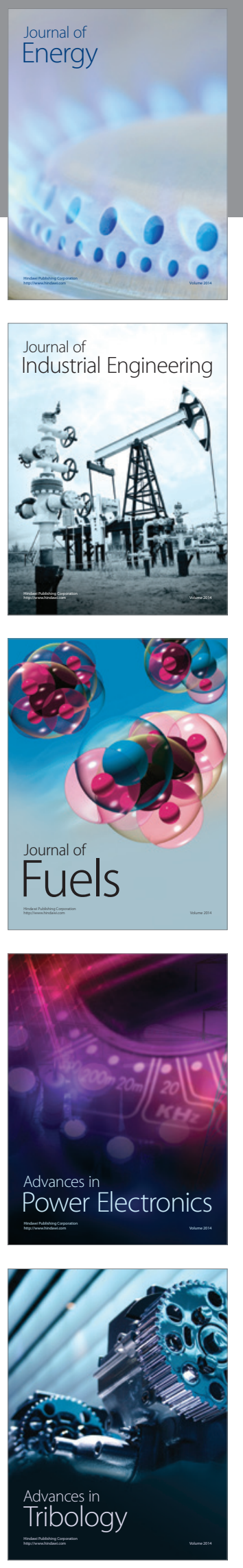
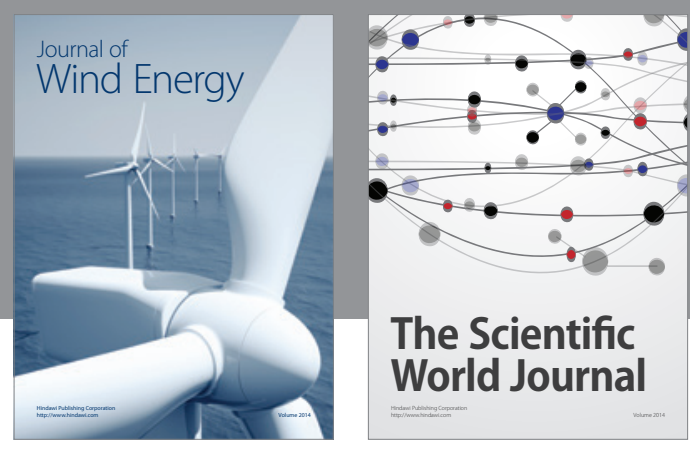

The Scientific World Journal

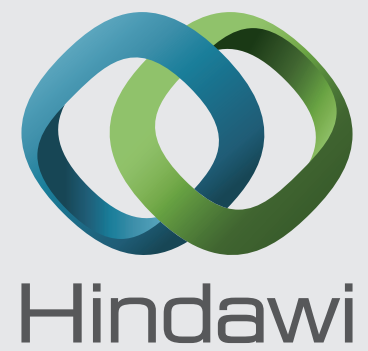

Submit your manuscripts at http://www.hindawi.com
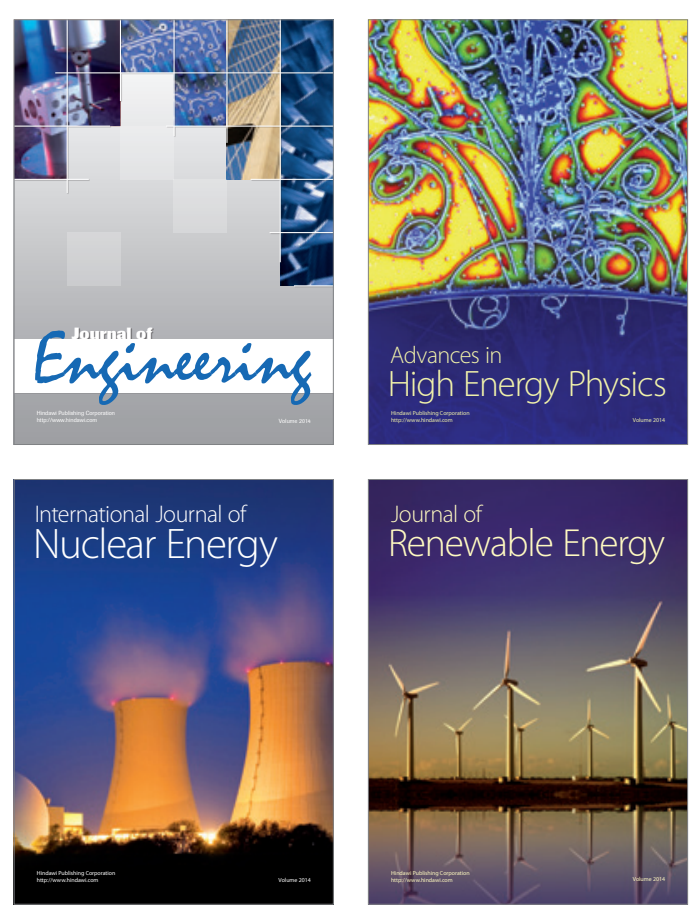

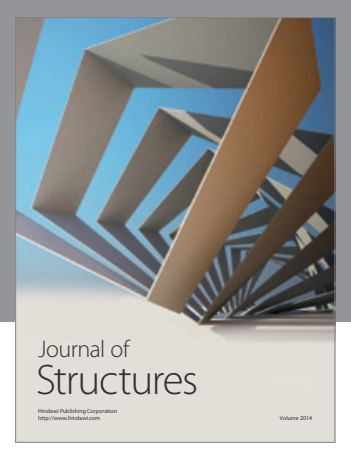

Rotating
Mechinery
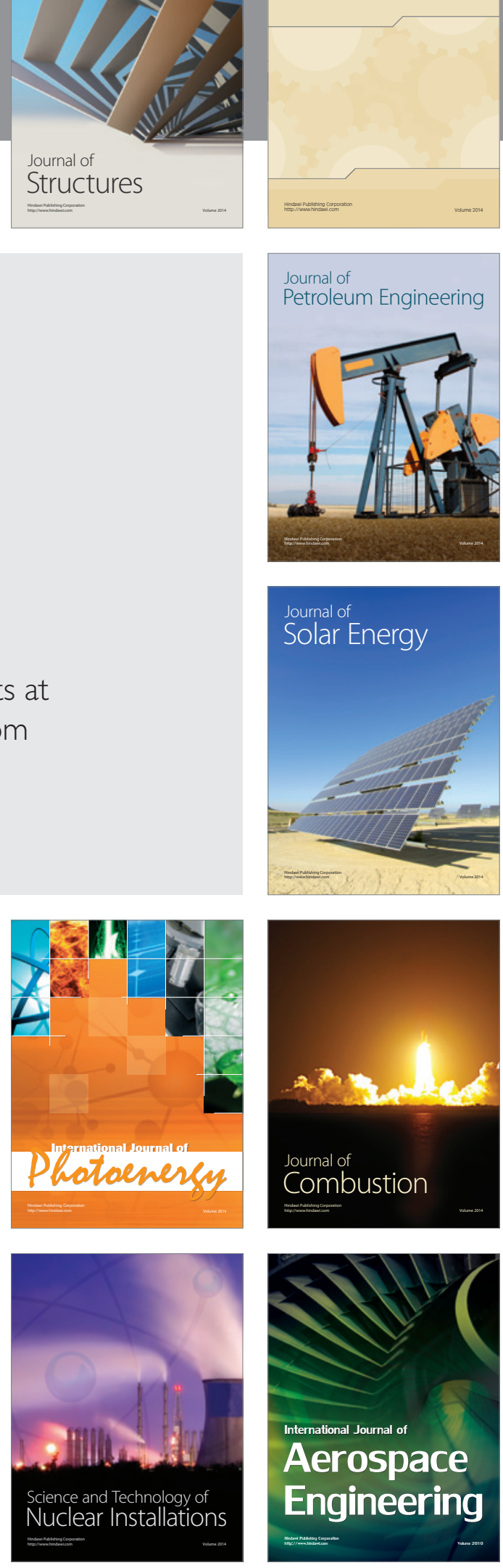